\title{
Accessing the Anti-Proliferating Activity of Tankyrase-2 Inhibitors via 2D, 3D-QSAR and Molecular Docking: Assessment of Structure Activity Relationships
}

\author{
Mervat H. El-Hamamsy \\ Department of Pharmaceutical Chemistry, Faculty of Pharmacy, Tanta University, El Giesh street, 31527, Tanta, Egypt.
}

\begin{tabular}{|c|c|}
\hline ARTICLE INFO & ABSTRACT \\
\hline Article history: & \multirow{10}{*}{$\begin{array}{l}\text { Tankyrases (TNKSs) have been implicated in many biological processes and have been proposed as a drug } \\
\text { target for cancer therapy. The human genome encodes two homologous isoforms, TNKS-1 and TNKS- } 2 \text {. This } \\
\text { study reported the first theoretical study of three-dimensional, two-dimensional quantitative structure activity } \\
\text { relationships and a docking analysis of a series of 2-arylquinazolin-4-one, 3-arylisoquinolin-1-one, } \\
\text { arylnaphthyridinone and aryltetrahydronaphthyridinone derivatives with remarkable TNKS-2 inhibiting } \\
\text { activities reported recently in literatures. The predictive ability of the QSAR models was assessed using internal } \\
\text { and external validation. 3D-QSAR model showed that the substituents R1 and R2 in studied compounds are key } \\
\text { modulators to enhance the TNKS-2 inhibition. The 2D-QSAR model, was based mainly on three 2D descriptors } \\
\text { and nine 3D descriptors. This suggested that TNKS-2 inhibition is predominantly controlled by steric properties } \\
\text { of the inhibitors. Docking study was carried out by using ligands docking on the active site of three different } \\
\text { crystal structures of TNKS-2 to understand the binding mode of these compounds as TNKS-2 inhibitors. We } \\
\text { discussed the structural requirements for selective and potent TNKS-2 inhibitors. Four potent inhibitors were } \\
\text { designed to be synthesized in the future. }\end{array}$} \\
\hline Received on: 11/07/2017 & \\
\hline Accepted on: 12/09/2017 & \\
\hline Available online: $30 / 12 / 2017$ & \\
\hline Key words: & \\
\hline Tankyrase, QSAR, Docking, & \\
\hline 2-arylquinazolin-4-one, 3 - & \\
\hline arylisoquinolin-1-one, & \\
\hline arylnaphthyridinone. & \\
\hline & \\
\hline
\end{tabular}

\section{INTRODUCTION}

Tankyrase (TNKS) was first identified in 1998 and found to interact with telomeric repeat binding factor (TRF1), a protein that binds to and protects the telomeric DNA. The human genome encodes two homologous isoforms, TNKS-1 and TNKS2 (Karlberg et al., 2010; Lehtiö et al., 2008). TNKSs are PARP (poly ADP-ribose polymerase) enzymes that produce poly(ADPribose) (PAR) to regulate multiple distinct cellular processes, including telomereelongation (De Rycker and Price, 2004; Riccio et al., 2016), control of the mitotic checkpoint and mediation of insulin-stimulated glucose uptake (Chi and Lodish, 2000). TNKSs serve as an associated protein in the Wnt signal transduction pathway (Martino-Echarri et al., 2016). As soon as TNKSs are positive telomerase regulators, inhibiting them reduces telomerase activity, enhances telomere shortening, and

* Corresponding Author

E-mail:mhamamsy@pharm.tanta.edu.eg may have an overall inhibitory effect on cancer (Lehtiö et al., 2008; Martino-Echarri et al., 2016). XAV939 was the first high potency TNKS inhibitory molecule identified (Haikarainen1 et al., 2016; Karlberg et al., 2010). TNKS-1 and TNKS-2 share 82\% sequence identity and similar secondary structure (Barkauskaite et al., 2015; Haikarainen1 et al., 2016). TNKS-2 exists as dimmer with two identical subunits. Each subunit is comprised of four distinct domains: catalytic, ankyrin-repeat, sterile alpha motif, and $\mathrm{N}$-terminal domains. The catalytic domain of TNKSs consists of two anti-parallel $\beta$-sheets surrounded by four $\alpha$-helices (Haikarainen1 et al., 2016; Lehtiö et al., 2008). The catalytic domain of TNKSs consists of a donor site and an acceptor site. The donor site can be divided into two parts, the nicotinamide and adenosine subsites. The catalytic domain includes three central amino acids (the conserved HYX triad) that are situated near the nicotinamide subsite. These residues are His1031, Tyr1060, Glu1138 for TNKS-2 (Haikarainen1 et al., 2016; Karlberg et al., 2010). 


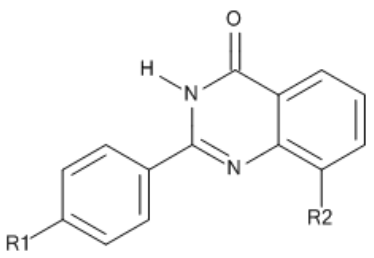

(A)

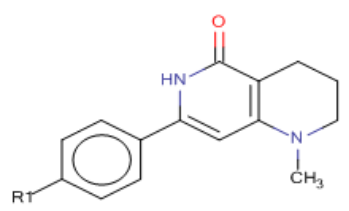

(D)<smiles>[R]c1cccc2c(=O)[nH]c(-c3ccc(Br)cc3)cc12</smiles>

(B)

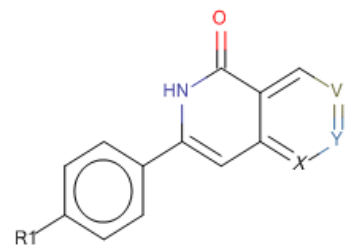

(C)

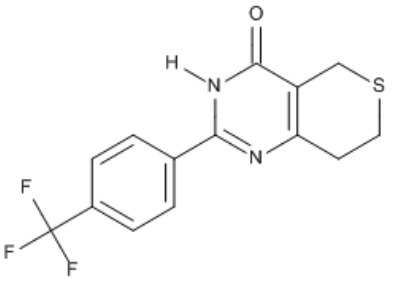

(E)

Fig. 1: General structures of 2-arylquinazolin-4-one (A), 3-arylisoquinolin-1-one derivatives (B) arylnaphthyridinone (C), aryltetrahydronaphthyridinone (D) and XAV939 (E) used in this modelling study.

TNKSs have been implicated in many biological processes and has been proposed as a drug target for cancer therapy. Altered levels of TNKSs expression have been reported in lung cancer (Wang et al., 2016), breast cancer (Gelmini et al., 2004), gastric cancer (Gao et al., 2011), bladder cancer (Gelmini et al., 2007), brain tumors (La Torre et al., 2013), colon carcinoma (Waaler et al., 2012) and pancreatic adenocarcinoma (Lehtiö et al., 2013). TNKSs inhibitors were classified into three main groups (Liscio et al., 2014);i) compounds that bind to nicotinamide subside and working as nicotinamide isosteres (Wahlberg et al., 2012) such as lactam-based pyrimidin-4-one (XAV939) (Huang et al., 2009) and non-lactam inhibitors (Shultz et al., 2013), ii) compounds that bind to adjacent induced pocket of the enzymes, adenoside sub-site, (Gunaydin and Huang, 2012; Bregman et al., 2013) and iii) dual binder compounds that simultaneously occupy both sites aforementioned (Hua et al., 2013).

Quantitative structure activity relationships (QSAR) are a mathematical model of statistical correlation between the variation in chemical structure (represented by molecular descriptors) and biological activity profile of a series of compounds. Molecular descriptors are either two-dimensional (2D) or three-dimensional (3D) (Todeschini et al., 2009). 2D and 3D-QSAR models help to understand the non-bonding interaction characteristics between the drug molecule and active site of the target site (Li et al., 2013). On the other hand, molecular docking studies provide the possible binding conformations of the ligands in a receptor. Combined with QSAR, they can provide information for designing new potential drugs (Jain et al., 2012; Villalobos et al., 2013).

In this computer-aided drug design study, a series of 2arylquinazolin-4-one (A) (Nathubhai et al., 2016), 3arylisoquinolin-1-one(B)(Paine et al., 2015), arylnaphthyridinone (C) and aryltetrahydronaphthyridinone (D)derivatives (Kumpan et al., 2015)with remarkable TNKS-2 inhibiting activities reported recently in literatures together with XAV939 (E) (Figure 1) were chosen to perform the first combined 2D, 3D-QSAR and docking studies. The aim of this work is to establish the first reliable 2D and3D-QSAR models to assess the structure activity relationships and to provide a guideline for designing novel anticancer TNKS-2 inhibiting drugs.

\section{MATERIALS AND METHODS}

\section{Dataset}

The dataset of 62 compounds, including XAV939 was retrieved from literatures (Kumpan et al., 2015; Nathubhai et al., 2016; Paine et al., 2015). The selected compounds for the data set shared the same assay procedure, with significant variations in their structures and potency profiles. They had $\mathrm{IC}_{50}$ values varying from 1.1 to $6200 \mathrm{nM}$ (Kumpan et al., 2015; Nathubhai et al., 2016; Paine et al., 2015). These were then converted into their negative logarithmic units, $\mathrm{pIC}_{50}$, values $\left[\mathrm{pIC}_{50}=-\log \mathrm{IC}_{50}(\mathrm{M})\right] .3 \mathrm{D}$ structures were drawn and geometry optimized using Marvin Sketch V5.11.5 (ChemAxon, 2017).

\section{D-QSAR, CoMFA}

The optimized structures were imported to SYBYL-X 2.1 (Sybyl, 2017) in *Mol2 file format. All compounds were minimized under the Tripos standard (TS) force field (Clark et al., 1989) with Gasteiger-Marsili atomic partial charges (Gasteiger and Marsili, 1980). Minimizations were done using the Powell method, in which calculations were set to terminate at an energy gradient value of $0.01 \mathrm{kcal} / \mathrm{mol}$. A genetic algorithm with linear assignment of hypermolecular alignment of datasets $\left(\right.$ GALAHAD $\left.^{\circledR}\right)$ is regarded as a superior tool for molecular alignment compared with classical common structural alignment (Zhao et al., 2011). 
The optimized structures were aligned using the "flexible alignment of ligands to each other" option in GALAHAD and set template molecule area to No template. The other parameters for calculation were set to default values. The chemical structures and biological activities of our dataset are shown in Table 1. For the development of 3D-QSAR model the dataset (62 compounds) was divided into a training set (44 compounds) to generate the model and a test set (18compounds) to evaluate the predictive ability of the resulting model.

\section{D-QSAR}

\section{Data preparation and descriptor selection}

The 3D-geometry of the compounds were built and energy minimized with Marvin 5.11.5software (ChemAxon 2017), and then further optimized by Molecular Operating Environment software (MOE version 2014.0901) (MOE, 2017). 2D and internal $3 \mathrm{D}$ descriptors for which alignment is not required were calculated for the data set using QuaSAR module of MOE software (MOE, 2017; Zhao et al., 2011). 2D descriptors only use the atoms and connection information of the molecule for the calculation while 3D coordinates and individual conformations are not considered. Internal 3D descriptors use 3D coordinate information about each molecule; however, they are invariant to rotations and translations of the conformation. To select the predominant descriptors affecting the activity of our data set, the descriptors $(1502 \mathrm{D}+90$ 3D-descriptors) were calculated for each molecule in the series and were reduced by eliminating out the descriptors with constant and near-constant values. Seven QuaSAR models were generated for each set of 2D-descreptors. Four QuasAr models were generated for each set of i3D-descreptors. Seven compounds with Z-score more than 2.5 were in the outlier and were eliminated from the data set. To reduce the number of descriptors considered for the study, both descriptors-contingency (a statistical application designed to assist in the selection of descriptors for QSAR) and correlation matrix were performed to limit the number of descriptors. A final set of three 2D-descriptors and nine i3Ddescriptors were identified to be significantly affecting pIC50 and was used in the construction of our QSAR model (Lakhlili, et al., 2016). The QuaSAR- module in MOE was used to generate the PLS QSAR model (MOE, 2017). Finally, the report of calculation was obtained and the model was saved as (*.FIT) file and was used to predict the activities of the test data set for external validation.

\section{Model validation}

Each obtained model (2D-QuaSAR and CoMFA models) was subjected to internal and external validation using the reported validation parameters of QSAR models (Gramatica, 2007; Roy, 2007). These parameters include root mean square error (RMSE), cross-validated RMSE, squared correlation coefficient $\left(\mathrm{R}^{2}\right)$ and cross-validated $\mathrm{R}^{2}\left(\mathrm{Q}^{2}\right.$ in case of CoMFA) for the training set in addition to $\mathrm{R}^{2}$ value of the test set.

\section{Molecular docking}

Molecular docking study was performed on selected inhibitors using two different softwares, FlexX module in LeadIT 2.2.0package (BioSolveIT, 2017) and MOE 2014.0901(MOE, 2017). The ligands were docked within the active site of 3 different crystal structures of TNK-2 available in the PDB (PDB code: 3U9H) (Protein data bank, 2017), (PDB code: 4UX4) (Protein data bank, 2017), and (PDB code: 3KR8) (Protein data bank, 2017).

The native ligand was removed, and the nicotinamide binding site was defined as all atoms within $8^{\circ} \mathrm{A}$ of the crystallographic ligand. Hydrogens were added to amino acid residues and all crystallographic water molecules were removed. Docking with flexible ligands and rigid protein was performed using standard parameters except that the number of runs was 20 . The scoring function is used for ranking the docked ligands into the active site (Tables $1 \mathrm{a}, \mathrm{b} \& \mathrm{c}$ ).

Table 1a: Experimental and predicted biological activities and residual values obtained by the CoMFA and 2D-QuaSAR models from training set and (test) set of compounds 1-8.

\begin{tabular}{|c|c|c|c|c|c|c|c|c|c|c|}
\hline $\begin{array}{c}\text { General chemical } \\
\text { structure }\end{array}$ & $\mathrm{NC}$ & $\mathbf{X}, \mathbf{V}, \mathbf{Y}$ & R1 & $\begin{array}{l}\mathrm{IC}_{50} \\
\mathrm{nM}\end{array}$ & $\mathrm{pIC}_{50}$ & $\begin{array}{c}\text { Pred. } \\
\text { pIC }_{50} \\
\text { CoM- FA }\end{array}$ & $\begin{array}{c}\text { Resid } \\
\text { Value } \\
\text { CoM- FA }\end{array}$ & $\begin{array}{l}\text { Pred. pIC } \\
\text { QuaS- AR }\end{array}$ & $\begin{array}{c}\text { Resid } \\
\text { Value } \\
\text { QuaS- AR }\end{array}$ & $\begin{array}{l}\text { Dock score* } \\
\quad \text { (clash) }\end{array}$ \\
\hline & 1 & $\mathrm{X}=\mathrm{N}$ & $\mathrm{H}$ & $5 \times 10^{3}$ & 5.30 & outlier & -0.22 & 5.56 & -0.26 & $-33.34(3.00)$ \\
\hline & 2 & $\mathrm{~V}=\mathrm{N}$ & $\mathrm{H}$ & $1.3 \times 10^{3}$ & 5.89 & 5.64 & 0.25 & 6.04 & -0.16 & - \\
\hline & 3 & $\mathrm{Y}=\mathrm{N}$ & $\mathrm{CH}_{3}$ & $6.2 \times 10^{3}$ & 5.21 & outlier & -0.20 & outlier & - & - \\
\hline & 4 & & $\mathrm{H}$ & 97 & 7.01 & 7.01 & 0.00 & outlier & - & $-31.59(4.12)$ \\
\hline & 5 & & $\mathrm{OCH}_{3}$ & 1.1 & 8.96 & 9.33 (test) & -0.37 & 9.86 (test) & -0.90 & $-32.92(3.72)$ \\
\hline & 6 & & $\mathrm{CF}_{3}$ & 1.5 & 8.82 & 8.74(test) & 0.08 & 8.92 (test) & -0.10 & - \\
\hline & 7 & & $\mathrm{Cl}$ & 21 & 7.68 & 7.81 & -0.13 & 7.85 & -0.17 & $-32.49(4.19)$ \\
\hline & 8 & & $\mathrm{Br}$ & 6.1 & 8.21 & 7.90 & 0.31 & 8.09 & 0.12 & $-32.51(4.18)$ \\
\hline
\end{tabular}

NC: number of compounds.

test set compounds are indicated for each model under the predicted values for each between practices.

*docking scores and (clashes) of some compounds docked on crystal structure 3KR8 using LeadIt. 
Table 1b: Experimental and predicted biological activities and residual values obtained by the CoMFA and 2D-QuaSAR models from training set and (test) set of compounds 9-49.

\begin{tabular}{|c|c|c|c|c|c|c|c|c|c|c|}
\hline $\begin{array}{l}\text { General chemical } \\
\text { structure }\end{array}$ & $\mathrm{NC}$ & R1 & $\mathbf{R} 2$ & $\mathrm{IC}_{50} \mathrm{nM}$ & $\mathrm{pIC}_{50}$ & $\begin{array}{l}\text { Pred. } \\
\text { pIC } \\
\text { CoMFA }\end{array}$ & $\begin{array}{l}\text { Resid } \\
\text { Value } \\
\text { CoMFA }\end{array}$ & $\begin{array}{l}\text { Pred. } \\
\text { pIC } \\
\text { QuaSAR } \\
\end{array}$ & $\begin{array}{l}\text { Resid } \\
\text { Value } \\
\text { QuaSAR }\end{array}$ & $\begin{array}{l}\text { Dock } \\
\text { score* (clash) }\end{array}$ \\
\hline & 9 & $\mathrm{H}$ & $\mathrm{OCH}_{3}$ & 1029 & 5.99 & 6.28 (test) & -0.29 & 5.95(test) & 0.04 & $-33.87(2.70)$ \\
\hline & 10 & $\mathrm{CH}_{3}$ & $\mathrm{OCH}_{3}$ & 167 & 6.78 & 6.98 & -0.20 & 7.22 & -0.44 & - \\
\hline & 11 & $\mathrm{CF}_{3}$ & $\mathrm{OCH}_{3}$ & 87 & 7.06 & 7.03 & 0.03 & 7.36 & -0.30 & - \\
\hline & 12 & $\mathrm{Cl}$ & $\mathrm{OCH}_{3}$ & 62 & 7.21 & 6.72 & 0.49 & 7.40 & -0.199 & $-33.18(1.84)$ \\
\hline & 13 & $\mathrm{Br}$ & $\mathrm{OCH}_{3}$ & 106 & 6.97 & 7.10 & -0.13 & 7.07 & -0.101 & - \\
\hline & 14 & $\mathrm{~F}$ & $\mathrm{OCH}_{3}$ & 459 & 6.34 & 6.41(test) & -0.07 & 6.53 (test) & -0.19 & - \\
\hline & 15 & $\mathrm{NO}_{2}$ & $\mathrm{OCH}_{3}$ & 863 & 6.06 & 6.20 & -0.14 & 5.92 & 0.137 & - \\
\hline & 16 & $\mathrm{NH}_{2}$ & $\mathrm{OCH}_{3}$ & 1076 & 5.97 & 6.59 & -0.62 & 6.23 & -0.27 & $-35.32(4.75)$ \\
\hline & 17 & $\mathrm{OCH}_{3}$ & $\mathrm{OCH}_{3}$ & 128 & 6.89 & 6.96 & -0.07 & 6.33 & 0.55 & $-32.99(2.53)$ \\
\hline & 18 & $\mathrm{H}$ & $\mathrm{H}$ & 2200 & 5.66 & 5.93 & -0.27 & 6.28 & -0.62 & $-32.83(2.45)$ \\
\hline & 19 & $\mathrm{CH}_{3}$ & $\mathrm{H}$ & 540 & 6.27 & 6.17 (test) & 0.10 & 6.28 (test) & -0.008 & - \\
\hline & 20 & $\mathrm{CF}_{3}$ & $\mathrm{H}$ & 133 & 6.88 & 6.64 & 0.24 & 7.52 & -0.37 & $-34.00(2.24)$ \\
\hline & 21 & $\mathrm{Cl}$ & $\mathrm{H}$ & 54 & 7.27 & 6.78 (test) & 0.49 & 6.83(test) & 0.44 & $-33.32(2.45)$ \\
\hline o & 22 & $\mathrm{Br}$ & $\mathrm{H}$ & 101 & 6.99 & 6.88 & 0.11 & 7.21 & -0.22 & - \\
\hline & 23 & $\mathrm{~F}$ & $\mathrm{H}$ & 1102 & 5.96 & 6.14 (test) & -0.18 & 5.96 (test) & 0.002 & - \\
\hline & 24 & $\mathrm{NO}_{2}$ & $\mathrm{H}$ & 259 & 6.59 & 6.86 & -0.27 & 6.09 & 0.496 & - \\
\hline & 25 & $\mathrm{NH}_{2}$ & $\mathrm{H}$ & 690 & 6.16 & 6.61(test) & -0.45 & 6.12 (test) & 0.04 & - \\
\hline & 26 & $\mathrm{OCH}_{3}$ & $\mathrm{H}$ & 611 & 6.21 & 6.09 & 0.12 & 6.69 & -0.48 & - \\
\hline & 27 & $\mathrm{OH}$ & $\mathrm{H}$ & 189 & 6.72 & 6.12 & 0.60 & 6.19 & 0.25 & $-31.42(3.95)$ \\
\hline & 28 & $\mathrm{CH}_{2} \mathrm{NH}-\mathrm{Cbz}$ & $\mathrm{H}$ & 45 & 7.35 & 7.28 & 0.07 & 7.08 & 0.26 & $-36.46(2.10)$ \\
\hline & 29 & $\mathrm{H}$ & $\mathrm{OH}$ & 180 & 6.74 & 6.45 & 0.29 & 6.99 & -0.25 & $-30.61(2.92)$ \\
\hline & 30 & $\mathrm{CH}_{3}$ & $\mathrm{OH}$ & 44 & 7.36 & 6.85 (test) & 0.51 & 7.51 & -0.16 & - \\
\hline & 31 & $\mathrm{CF}_{3}$ & $\mathrm{OH}$ & 25 & 7.60 & 7.33(test) & 0.27 & 7.56 & 0.04 & $-31.72(3.17)$ \\
\hline & 32 & $\mathrm{Cl}$ & $\mathrm{OH}$ & 49 & 7.31 & 7.29 & 0.02 & 7.27 & 0.03 & $-31.07(2.93)$ \\
\hline & 33 & $\mathrm{Br}$ & $\mathrm{OH}$ & 15 & 7.82 & 7.41 & 0.41 & 7.85 & -0.03 & $-31.18(2.93)$ \\
\hline & 34 & F & $\mathrm{OH}$ & 263 & 6.58 & 6.65 & -0.07 & 6.88 & -0.30 & - \\
\hline & 35 & $\mathrm{NO}_{2}$ & $\mathrm{OH}$ & 191 & 6.72 & 7.01 & -0.38 & 6.99 & -0.27 & - \\
\hline & 36 & $\mathrm{NH}_{2}$ & $\mathrm{OH}$ & 219 & 6.66 & 6.76 & -0.10 & 6.39 & 0.26 & $-33.58(4.16)$ \\
\hline & 37 & $\mathrm{OH}$ & $\mathrm{OH}$ & 86 & 7.07 & 7.25 (test) & -0.18 & 6.94(test) & 0.13 & - \\
\hline & 38 & $\mathrm{H}$ & $\mathrm{CH}_{3}$ & 42 & 7.38 & 7.33 & 0.05 & 7.62 & -0.25 & - \\
\hline & 39 & $\mathrm{CH}_{3}$ & $\mathrm{CH}_{3}$ & 7 & 8.15 & 8.05 & 0.10 & 7.73 & 0.41 & $-35.21(4.19)$ \\
\hline & 40 & $\mathrm{CF}_{3}$ & $\mathrm{CH}_{3}$ & 10 & 8.00 & 8.07 & -0.07 & 7.88 & 0.11 & $-34.37(4.12)$ \\
\hline & 41 & $\mathrm{Cl}$ & $\mathrm{CH}_{3}$ & 33 & 7.48 & 8.16 & -0.68 & outlier & & $-33.14(5.74)$ \\
\hline & 42 & $\mathrm{Br}$ & $\mathrm{CH}_{3}$ & 6 & 8.22 & 8.28 (test) & -0.06 & 7.83 & 0.38 & $-33.49(3.80)$ \\
\hline & 43 & $\mathrm{~F}$ & $\mathrm{CH}_{3}$ & 40 & 7.40 & 7.55 & -0.15 & 7.30 & 0.08 & - \\
\hline & 44 & $\mathrm{NO}_{2}$ & $\mathrm{CH}_{3}$ & 30 & 7.52 & 7.28 & 0.24 & 7.19 & 0.32 & - \\
\hline & 45 & $\mathrm{NH}_{2}$ & $\mathrm{CH}_{3}$ & 3 & 8.52 & 7.48 & 1.04 & outlier & - & $-39.17(3.07)$ \\
\hline & 46 & $\mathrm{OCH}_{3}$ & $\mathrm{CH}_{3}$ & 12 & 7.92 & 8.04 & -0.12 & 7.15 & 0.76 & - \\
\hline & 47 & $\mathrm{OH}$ & $\mathrm{CH}_{3}$ & 6 & 8.22 & 7.98 & 0.24 & 7.54 & 0.67 & $-35.34(3.99)$ \\
\hline & 48 & $\mathrm{CH}_{2} \mathrm{NH}-\mathrm{Cbz}$ & $\mathrm{CH}_{3}$ & 73 & 7.14 & 7.30 & -0.16 & 7.43 & -0.30 & $-37.16(3.64)$ \\
\hline & 49 & $\mathrm{CH}_{2} \mathrm{~N}^{+} \mathrm{H}_{3} \mathrm{Br}^{-}$ & $\mathrm{CH}_{3}$ & 43 & 7.37 & 7.37 & 0.00 & 7.59 & -0.23 & - \\
\hline
\end{tabular}

NC: number of compound.

test set compounds are indicated for each model under the predicted values for each between practices.

*docking scores and (clashes) of some compounds docked on crystal structure 3KR8 using LeadIt.

Table 1c: Experimental and predicted biological activities and residual values obtained by the CoMFA and 2D-QuaSAR models from training set and (test) set of compounds 50-62.

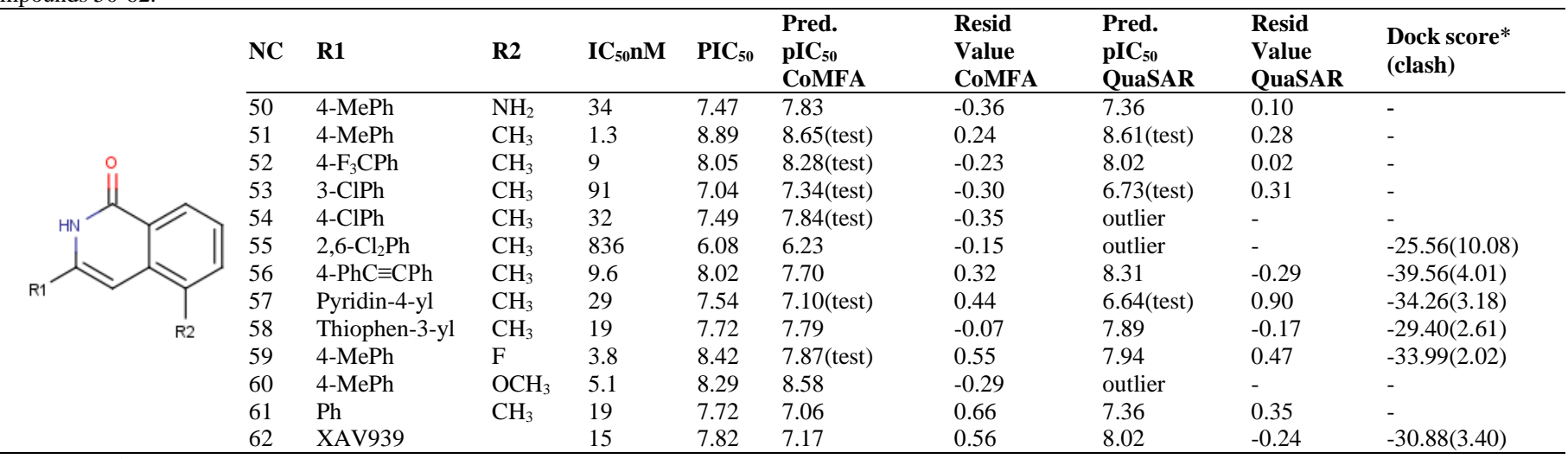

NC: number of compound.

test set compounds are indicated for each model under the predicted values for each between practices.

*docking scores and (clashes) of some compounds docked on crystal structure 3KR8 using LeadIt. 


\section{RESULTS AND DISCUSSION}

\section{D-QSAR CoMFA}

OptiSim Diversity Algorithm, which is one of dissimilarity-based algorithms in the Tripos module in SYBYL software, was used for selection of structurally diverse sets of compounds in our data set to ensure coverage of the largest possible expanse of chemical space in the search for bioactive molecules (Clark, 1997). For the development of CoMFA model, the complete set of these molecules (62 compounds) were divided into a training set (44 compounds) to generate the models and a test set (18 compounds) to evaluate the predictive ability of the resulting models. The general structural formulae of the studied compounds are shown in Tables $1 \mathrm{a}, \mathrm{b}$ and $\mathrm{c}$.

A statistically significant 3D-QSAR model was obtained by using the CoMFA method in SYBYL X-2.1.1 to construct the model. In the CoMFA model, initial PLS analysis of the aligned training set was done using a default data filter of $2.0 \mathrm{kcal} / \mathrm{mol}$ and the Tripos standard field. After omitting two outliers, (compounds1 and 3), \& using MOLPROP-AREA (1D-descriptor) as an additional independent variable in 3D-QSAR models, better internal validation parameters $\left(\mathrm{R}^{2}, \mathrm{Q}^{2}\right.$ and standard error) were obtained from a training set of 42 compounds as opposed to the model derived from 44 compound (Tables 1a,b \& c).

\section{Validating the model}

Internal validation of the final CoMFA model showed a cross-validation coefficient $\left(\mathrm{Q}^{2}\right)$ of 0.588 for eight components used. The non-cross-validated PLS analysis results in a conventional $\mathrm{R}^{2}$ of 0.889 and an estimated standard error of 0.189 . Also, the steric field descriptors explain $77.80 \%$ of the variance, the electrostatic descriptors explain $2.27 \%$ of the variance and the MOLPROP-AREA descriptors explain $19.93 \%$ of the variance. External validation (Gramatica, 2007; Tropsha, 2010) of the developed model is achieved by calculating the predicted biological activity for training and test sets using CoMFA model. The calculated residual values revealed a satisfactory predictive ability of our developed model as shown in Tables 1 (a, b \& c).
Scatter correlation plots for experimental and predicted activities of ligands elicited significant linear correlation and moderate differences between the experimental and predicted values as shown in Figure 2 ( $a$ and $b$ ).

Graphical interpretation of CoMFA model: To visualize the information contained in the 3D-QSAR model, maps for CoMFA contours was generated, which provided a major understanding of the biological activities of studied compounds. The steric and electrostatic CoMFA contour fields are shown in Figures 3 and 4. In the steric field CoMFA, the green contours represent regions where bulky groups enhance the biological activity, while bulky groups decrease activity in contact with yellow regions. Furthermore, in the electrostatic fields CoMFA, blue contours indicate regions where the positive charge is desirable (electron withdrawing group enhances the activity) and red contours indicate the regions where negative charge is desirable (electron donating group enhances the activity) (Villalobos et al., 2013; Li et al., 2013). The contour maps of our model included two green steric regions at R1 and R2 positions (Figure 1, A and B) and a yellow steric region at 2 and 6 position of the phenyl group (two ortho positions). The electrostatic map showed a predominant red contour which indicated that negatively charged substituent is desirable (electron donating group enhance activity). The molecular structure of compounds23 and 55have been displayed in the fields as shown in Figures 3 and 4.

Compound (23) with ap-flourophenyl group (R1=F) showed low activity because the steric bulky atom is desirable (green contour) and electron donor is favored (red contour) at this para position. That is why analogues with $\mathrm{R} 1=\mathrm{Br}$ (compounds 8 , $22,33,42$ ) and $\mathrm{R} 1=\mathrm{OCH}_{3}$ (compounds $5,17,46$ ) are more active than corresponding isomers with $\mathrm{R} 1=\mathrm{H}$ (compounds 4, 9, 18, 29, 38), $\mathrm{R} 1=\mathrm{F}(14,23,34,34)$ and isomers with $\mathrm{R} 1=\mathrm{Cl}$ (compounds 7 , $21,32,41)$ because the steric contribution with desirable bulky group at this region (green contour) represent $77.80 \%$ of the variance, while electrostatic contribution is only $2.27 \%$ and the MOLPROP-AREA descriptors explain $19.93 \%$ of the variance. Consequently, both bulky electron donors and acceptors enhance the activity as shown in Figure 3.

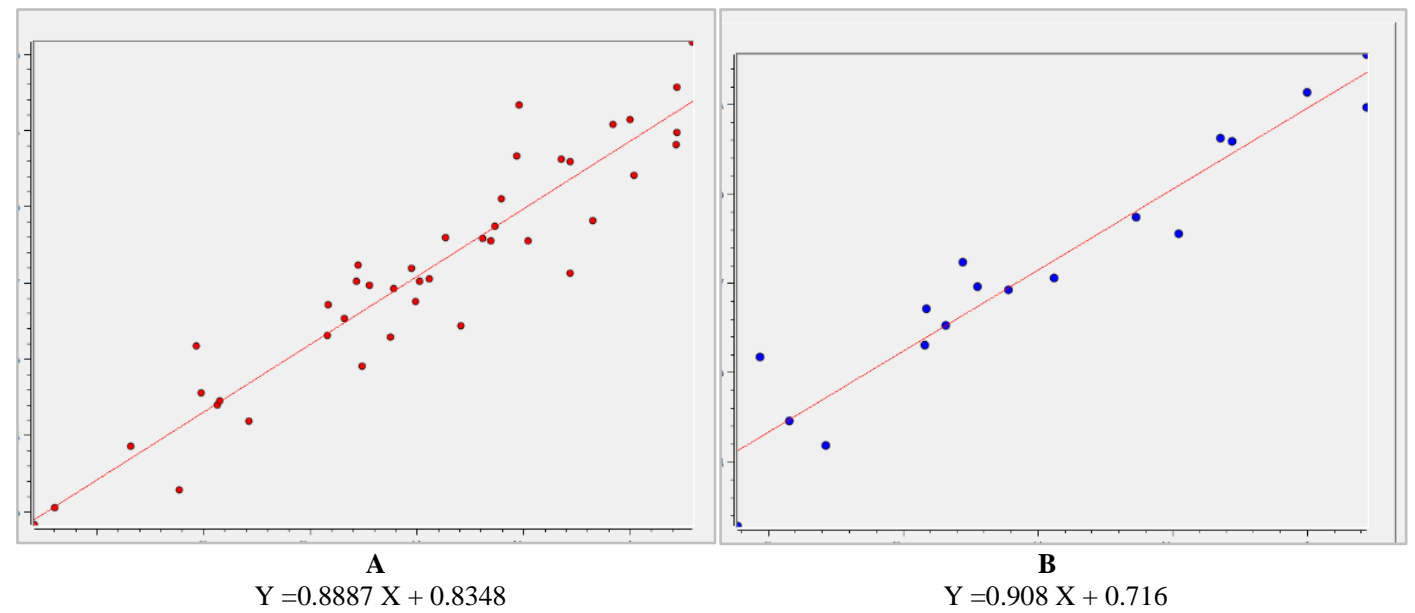

Fig. 2: Correlation plot between predicted pIC50versus experimental pIC50for (a) the training set and (b) the test set using CoMFA model. 


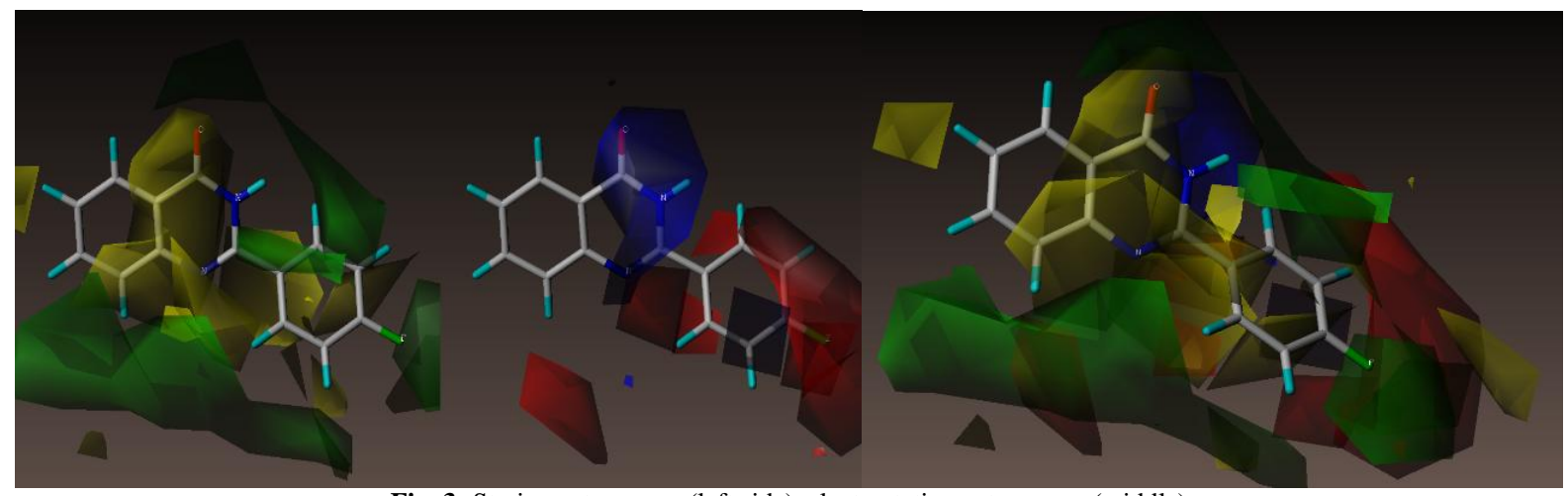

Fig. 3: Steric contour map (left side), electrostatic contour map (middle) and overlay of contour maps (right side) of CoMFA model using compound (23) as a model.

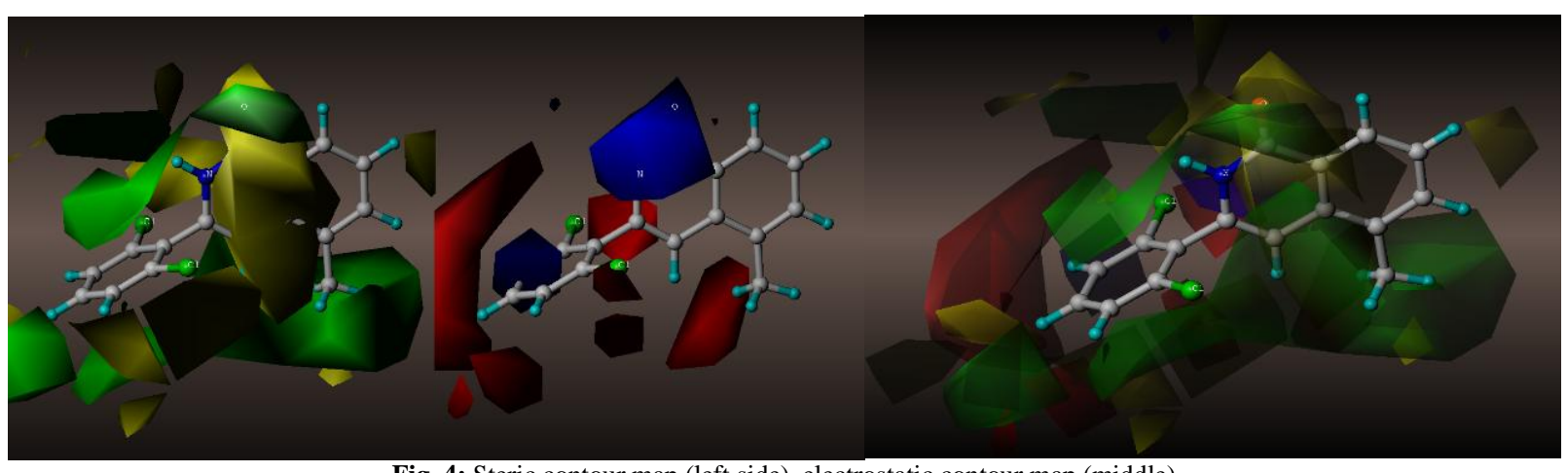

Fig. 4: Steric contour map (left side), electrostatic contour map (middle)

and overlay of contour maps (right side) of CoMFA model using compound (55) as a model.

2,6-dichlorophenyl group in the compound (55) lowered the potency because steric bulk is undesirable (yellow contour) around the two ortho positions. On the other hand, electron donor is favored (red contour) at this position. At the isoquinolinonering where, R2 = methyl, short, bulky group electron donor is favored and increase the biological activity because this position surrounded by green (with yellow contour beneath it)and red contours. Since short electron donor is desirable in this region, it was observed that all compounds with $\mathrm{R} 2=\mathrm{CH}_{3}$ (compounds, 3849), $\mathrm{NH}_{2}$ (compound 50) or $\mathrm{OH}$ (compounds 29-37) showed high biological activity compared to analogues with $\mathrm{R} 2=\mathrm{H}$ (compounds, 18-27) as well as $\mathrm{R} 2=\mathrm{OCH}_{3}$ groups (compounds, 917) as shown in figure 4.

\section{D-QSAR}

For the development of 2D-QuaSAR model the data set of 55 compounds, after eliminating seven outlier compounds with Z-score more than 2.5 (compounds 3, 4, 41, 45, 54, 55, 60), were divided into a training set (43 compounds) to generate the model and a test set (12 compounds) to evaluate the predictive ability of the resulting model. The test compounds were selected manually in order to consider the structural diversity and a wide range of anti-malarial activity. The in vitro TNKS-2 Inhibition Concentration $\quad\left[\mathrm{IC}_{50}(\mathrm{nM})\right]$ values were converted to the logarithmic scale $\mathrm{pIC}_{50}$ and used as dependent variables in
2D-QSAR analysis as shown in Tables 1a, b \& c. Twenty-five models were constructed. The best model was chosen based on its statistical validation parameters and represented by the following equation:

pIC50 $=58.99146+0.55492 *$ AM1_IP $-8.56710 *$ FASA +$0.41808 *$ FCASA $++1.78262 *$ PM3_HOMO + $11.24403 *$ VAdjEq - $21.39089 *$ vsurf_CW1 + $3.73822 *$ vsurf_CW2 $0.14832 *$ vsurf_CW3 $+8.21106 *$ vsurf_CW5 $-7.91040 *$ vsurf_CW6 - $7.86719 *$ BCUT-SMR_1 $+6.67410 *$ BCUT_PEOE_2

The involved molecular descriptors are:

VAdjEq: Atom Counts and Bond Counts, 2D descriptor

BCUT_PEOE_2 and BCUT_SMR_1: Adjacency and Distance Matrix,2D descriptors

AM1_IP and PM3_HOMO: MOPAC, 3D descriptors vsurf_CW*:Surface Area, Volume and Shape, 3Ddescriptors FASA+ and FCASA+: Conformation Dependent Charge,3D descriptors

The developed 2D model was based mainly on three 2D descriptors and nine 3D descriptors. This suggested that TNKS-2 inhibition is predominantly controlled by steric properties of the inhibitors, which is also supported by our developed CoMFA model. The vsurf_CW ${ }^{*}$ descriptors depend on the structure connectivity and conformation. These descriptors have been 
shown to be useful in pharmacokinetics property prediction (Cruciani et al., 2000). The conformation dependent charge descriptors, FASA+ and FCASA+, depend upon the stored partial charges of the molecules and their conformations. They measure the relative fractional water accessible surface area of all atoms with positive partial charge and a positive charge weighted surface area respectively (Stanton and Jurs, 1990), which revealed the importance of partial positive charge and presence of electron donors on activity as provided by our CoMFA model as well.

\section{Validating the model}

The internal validation parameters for the developed model was found to be accepted, where the $\mathrm{R}^{2}=0.795, \mathrm{R}^{2}(\mathrm{cv})=$ $0.607, \mathrm{RMSE}=0.336$, and RMSE $(\mathrm{cv})=0.483$. The difference between the $R^{2}$ and $R^{2}$ (cv) value is 0.188 which indicates that the number of descriptors involved in the QSAR model is acceptable. The number of descriptors is not acceptable if the difference is more than 0.3 (Veerasamy et al., 2011). External validation of the model is achieved by calculating the predicted pIC50 for the training and test sets compounds. The residual values were calculated and were less than 1 as shown in Tables ( $1 \mathrm{a}, \mathrm{b}$ and $\mathrm{c}$ ) and Figures (5 and 6). The model's predictive power was evaluated using $\mathrm{R}^{2}$ value of the test set and was the highest (0.795) compared to other models, as shown in the correlation plot of actual pIC50 versus predicted pIC50 for test set as shown in Figure 7. Moreover, the correlation plot between actual pIC50 and residual values for test set showed the lowest correlation value (0.385) i.e. it has good predictively, Figure8.

Both models revealed the importance of topological properties of the ligands especially the surface area (MOPLPROP_AREA descriptor in CoMFA and MOPAC, vsurf $\mathrm{CW}^{*}$ descriptors in QuaSAR). By calculating the total surface area, polar surface area, solvent accessible surface area $\log P$ for the four different nuclei included in this study exemplified by compounds 1, 4, 38 and 61 as shown in Table 2, we can conclude that isoquinolin-1-one is the most active ring. It has large $\log \mathrm{P}$ value, a large molecular surface area in $3 \mathrm{D}$ and the smallest polar surface area as shown in Table 2.

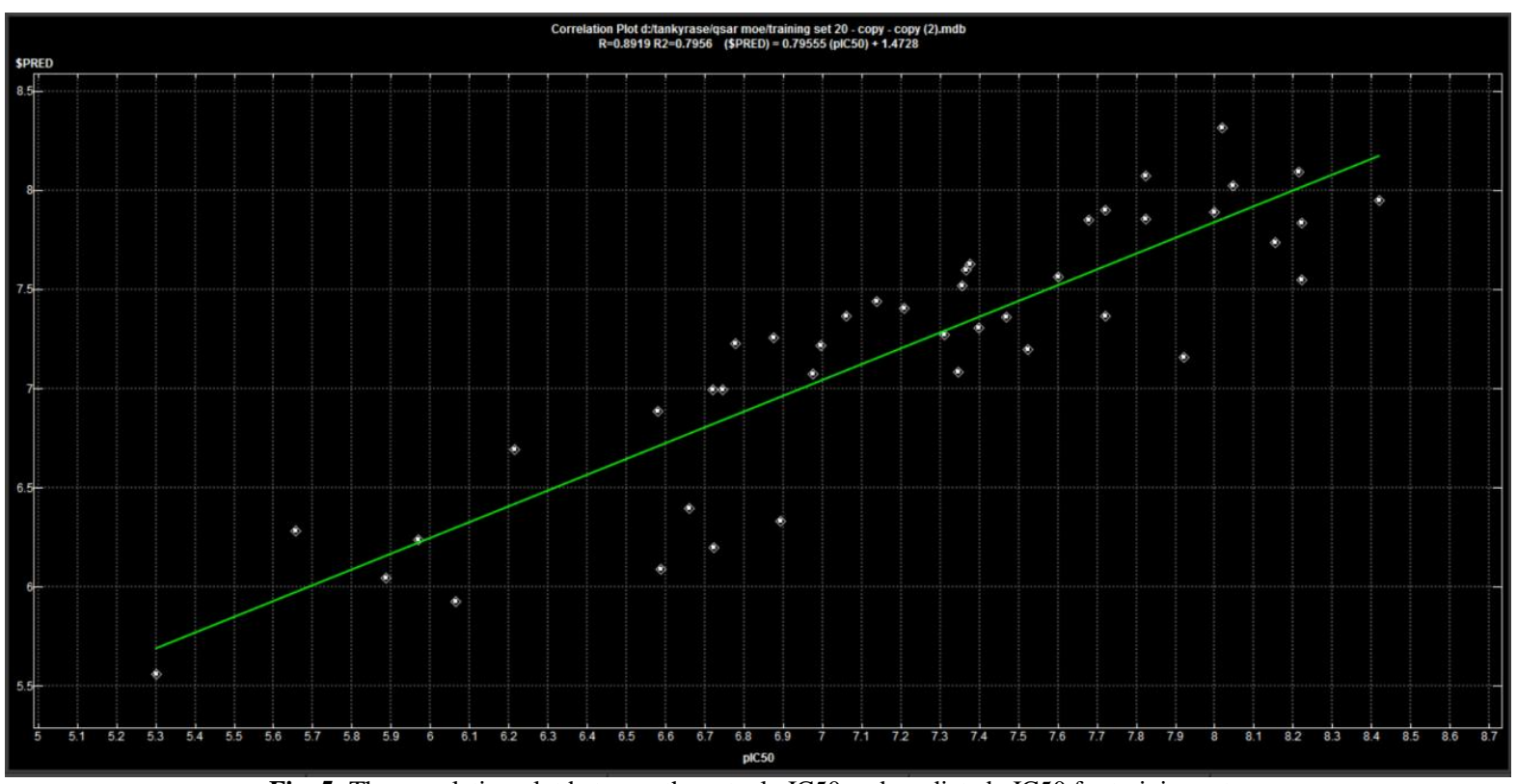

Fig. 5: The correlation plot between the actual pIC50 and predicted pIC50 for training set.

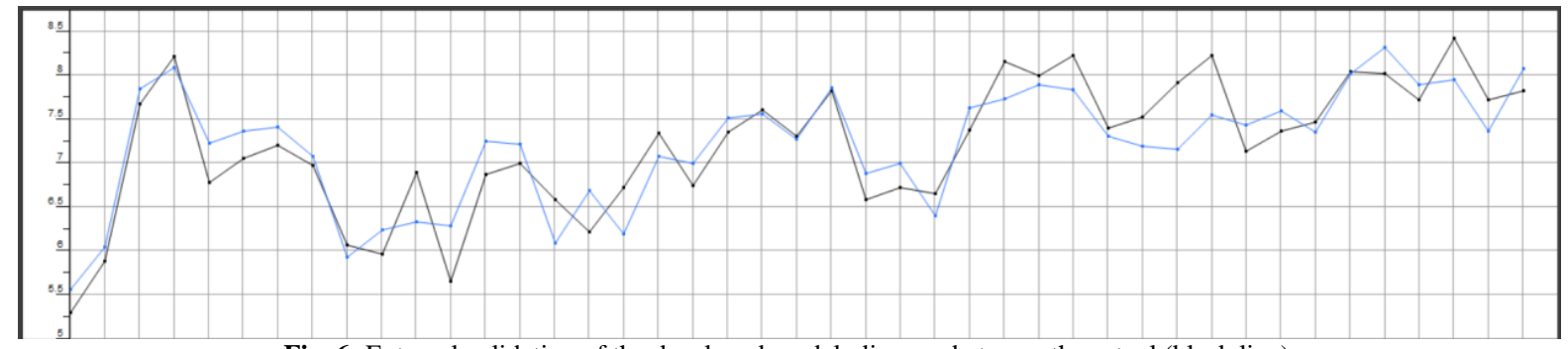

Fig. 6: External validation of the developed model, diagram between the actual (black line) and predicted (blue line) pIC50 for the training set where residual values were less than 1 . 


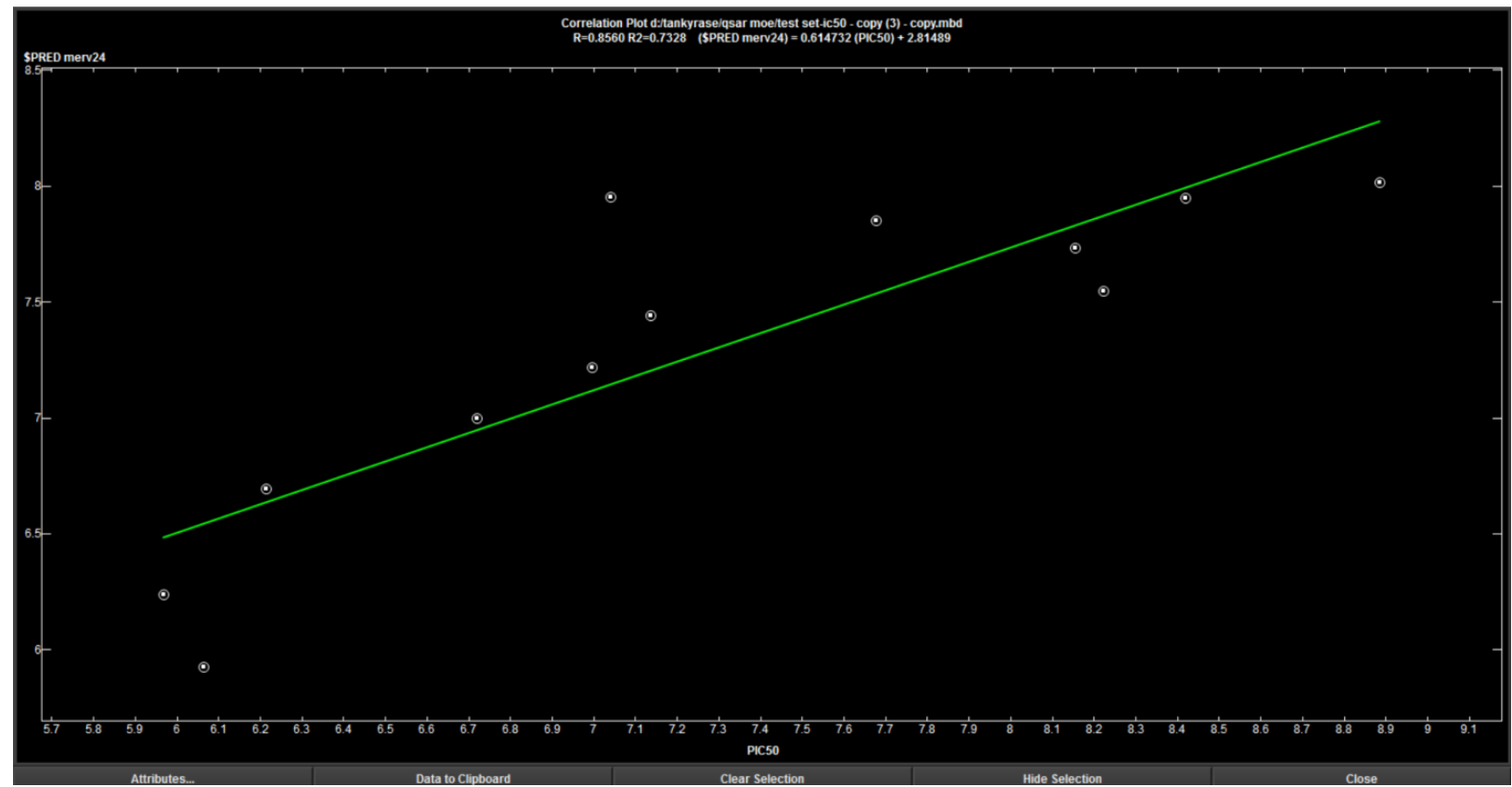

Fig. 7: External validation of the developed QuaSAR model, the correlation plot of actual pIC50 versus predicted pIC50 for test set.

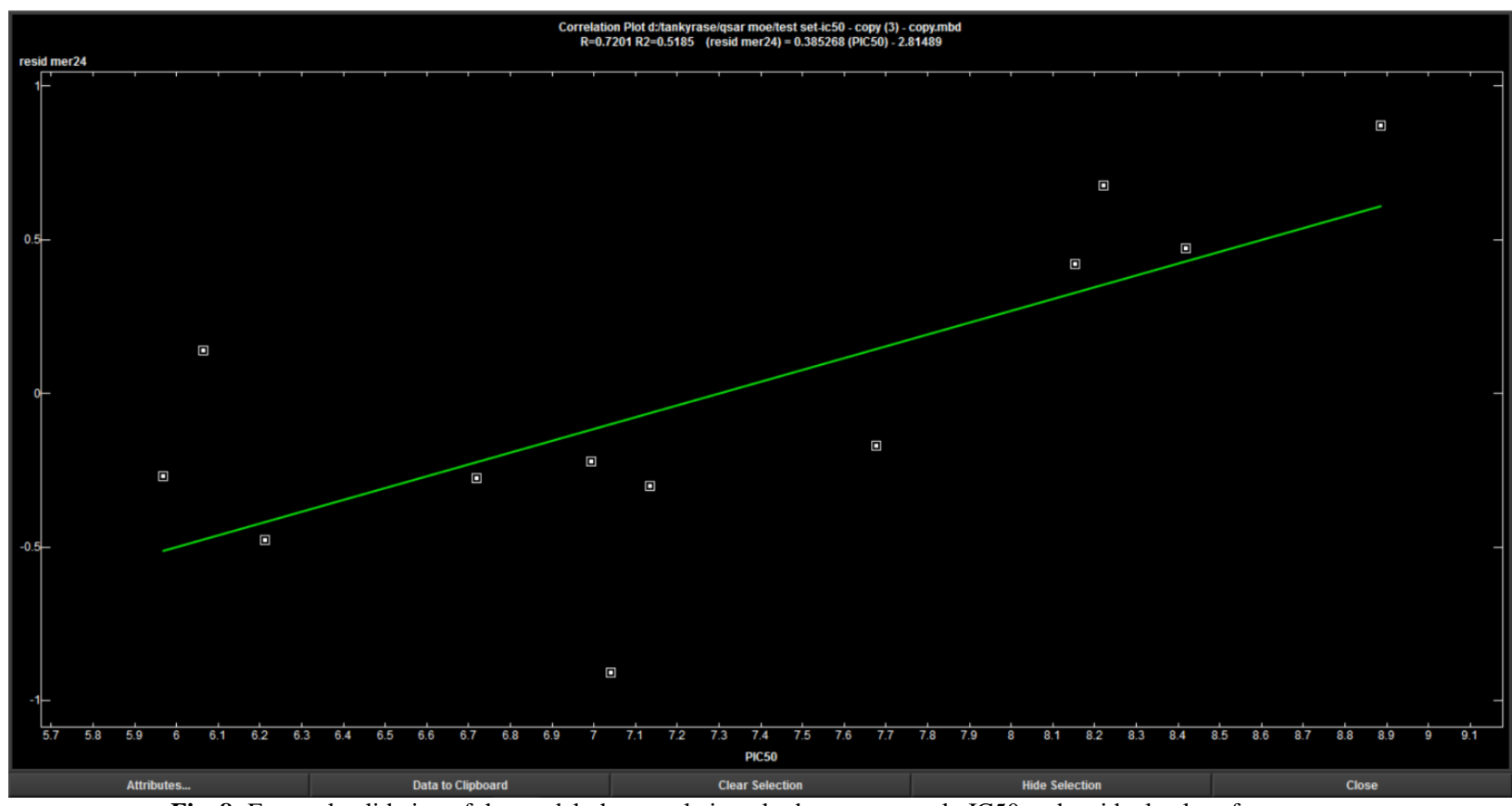

Fig. 8: External validation of the model, the correlation plot between actual pIC50 and residual values for test set.

Table 2: Calculated topological parameters for four heterocyclic nucleus included in this study showing the influence of lipophilicity, dipole moment and surface area properties on biological activity.

\begin{tabular}{|c|c|c|c|c|c|}
\hline \multicolumn{2}{|c|}{ Parameters } & Compound 1 & Compound 4 & Compound 38 & Compound 61 \\
\hline$\overline{0}$ & IC50 nM & 5000 & 97 & 42 & 19 \\
\hline o & $\log \mathrm{P}$ & 1.64 & 1.46 & 3.14 & 3.14 \\
\hline 0 & Dipole moment & 6.45 & 7.53 & 4.05 & 4.17 \\
\hline o & Molecular surface area (Van der Waals (3D)) & 289.33 & 344.47 & 326.69 & 329.16 \\
\hline c & Polar surface area (2D) & 41.99 & 32.34 & 41.46 & 29.10 \\
\hline c & ASA & 395.29 & 427.40 & 438.18 & 434.10 \\
\hline c & ASAt & 230.81 & 295.57 & 261.55 & 265.32 \\
\hline c & ASA- & 163.86 & 131.84 & 176.62 & 168.69 \\
\hline$c$ & ASA_H & 336.05 & 388.98 & 395.10 & 390.14 \\
\hline c & ASA_P & 58.24 & 38.42 & 43.08 & 43.87 \\
\hline
\end{tabular}

ASA: water accessible surface area, ASA+: Water accessible surface area of all atoms with positive partial charge, ASA-: Water accessible surface area of all atoms with negative partial charge, ASA_H: Water accessible surface area of all hydrophobic atoms, ASA_P: Water accessible surface area of all polar atoms. All parameters were calculated by Marvin sketch. 


\section{Molecular Docking Analysis}

Docking study was carried out by using ligands docking on the active site of three different crystal structures of TNKS-2 (PDB: 3U9H, 4UX4 and 3KR8) using two different softwares, MOE (MOE, 2017) and LeadIt (BioSolveIT, 2017),to understand the binding mode of 2-arylquinazolin-4-one (A), 3arylisoquinolin-1-one (B) arylnaphthyridinone (C) and aryltetrahydronaphthyridinone (D) derivatives as TNKS-2 inhibitors. To validate the ligands docking, the protein was docked with nicotinamide and XAV939. Nicotinamide as well as all tested compounds has the essential nicotinamide pharmacophore requirement for inhibiting TNKS-2.They form three $\mathrm{H}$-bonds with Gly1032 and Ser1068. Hydrophobic interaction with Tyr1060 and Tyr1071 was also observed. Figure 9 gives details of their docking analysis.

The aforementioned binding interactions were not enough for potent inhibitors. Strong inhibitor, XAV939, was docked in the active site of the catalytic domain of TNKS-2 as shown in Figure 10. The 3D pose showed the nicotinamide subsite as a deep pocket having Gly1032 and Ser1068 at the bottom of the pocket where XAV939 form three H-bonds mimic nicotinamide.
It binds to the HYD triad of the active site by forming $\mathrm{H}$ bond between sulfur and Glu1138 and hydrophobic attraction force with His1031 and Tyr1060. The lipophilicity of the active site is due to Pro1034 and Phe1035 in the F-loop as well as Ile1075 in the G-loop (Haikarainen1 et al., 2014). XAV939 formed $\pi-\pi$ stacking with Tyr1071. Hydrophobic attraction forces with Phe1035, His1048, Tyr1071 and Ile1075 were also observed. The contour drawn around the ligand is not broken (black dotted curved line) and is indicative of the presence of enough steric room for the ligand inside the binding pocket.

Analysis of the docking interaction of potent inhibitors, compounds 27, 45 and 47, on TNKS-2 crystal structures, 4UX4, $3 \mathrm{U} 9 \mathrm{H}$ and $3 \mathrm{KR} 8$, demonstrated the same ordinary binding interactions mimic nicotinamide by using MOE program. On the other hand, LeadIt program captured H-bond between both $\mathrm{NH}_{2}$ and $\mathrm{OH}$, in compounds 45 and 47respectively, and Ala1049 which explained their high activity as shown in Figure 11.Analysis of the docking mode of compounds,29-37 and 50, showed an additional H-bond interaction of hydroxyl and amino groups, respectively, with Met1113 which explained their high potency as shown in Figure 12.

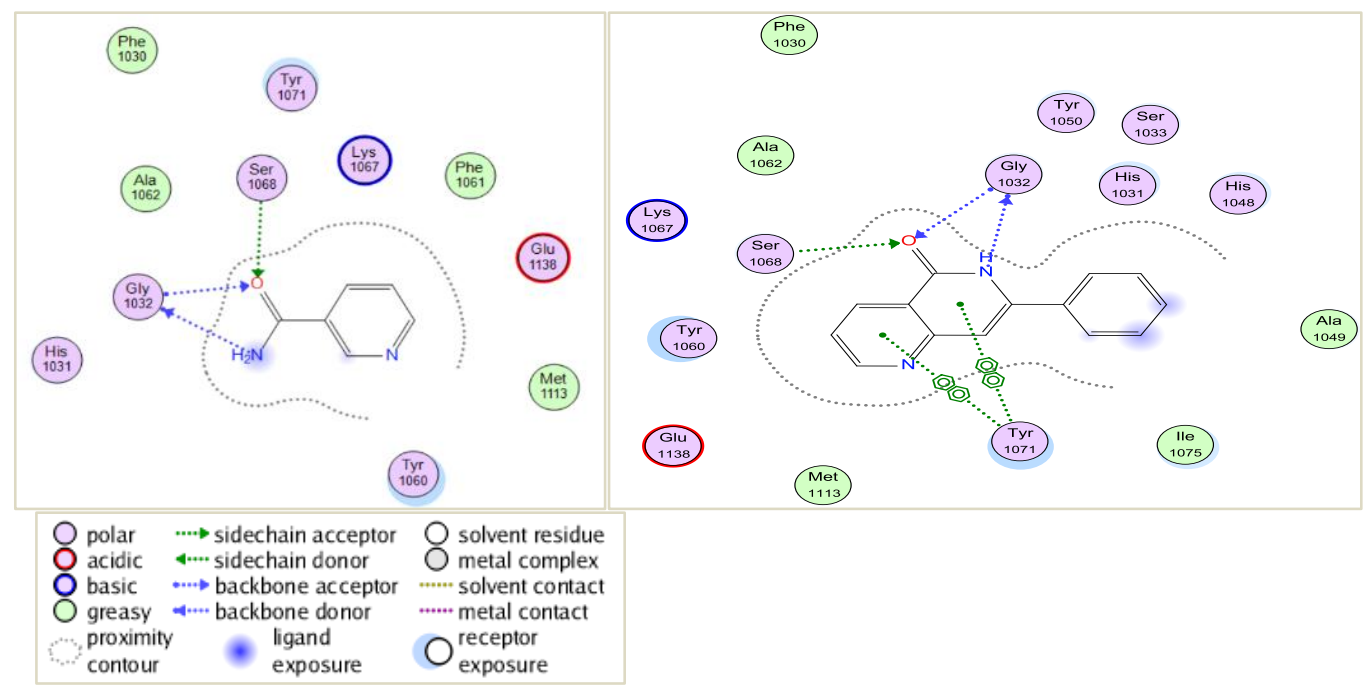

Fig. 9: 2D-pose of the interaction made by nicotinamide (left) and compound 1(very week inhibitor) (right), on 3U9H using MOE.

$\mathrm{H}$-bonds are indicated as dotted arrows. Both are showing hydrogen bond interaction with Gly1032, Ser1068. Both had hydrophobic attraction force indicated as a blue shadow around the amino acid residue, with Tyr1060, Tyr1071. Compound 1 showed $\pi-\pi$ stacking, as indicated by green dotted line, with Tyr1071.
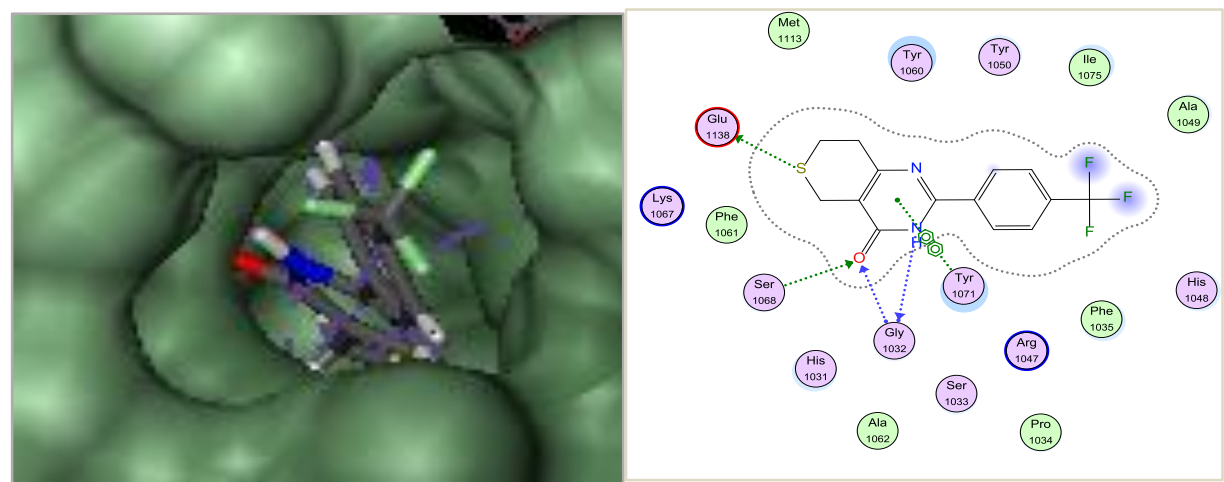

Fig. 10: 3D-pose (left, by leadIt) and 2D-pose (right, by MOE) of the interaction made by XAV939, on 3U9H

3H-bonds are indicated as dotted arrows with Gly1032, Ser1068, Glu1138, hydrophobic attraction force indicated as light-blue halos around the amino acid residue, with His1031, Phe1035, His1048, Tyr1060, Ile1075, $\pi$ - $\pi$ stacking, as indicated by green dotted line, with Tyr1071, 2 fluoride atoms with high solvent accessible surface area (blue smudge) are in the interior region of the binding pocket filled with water 


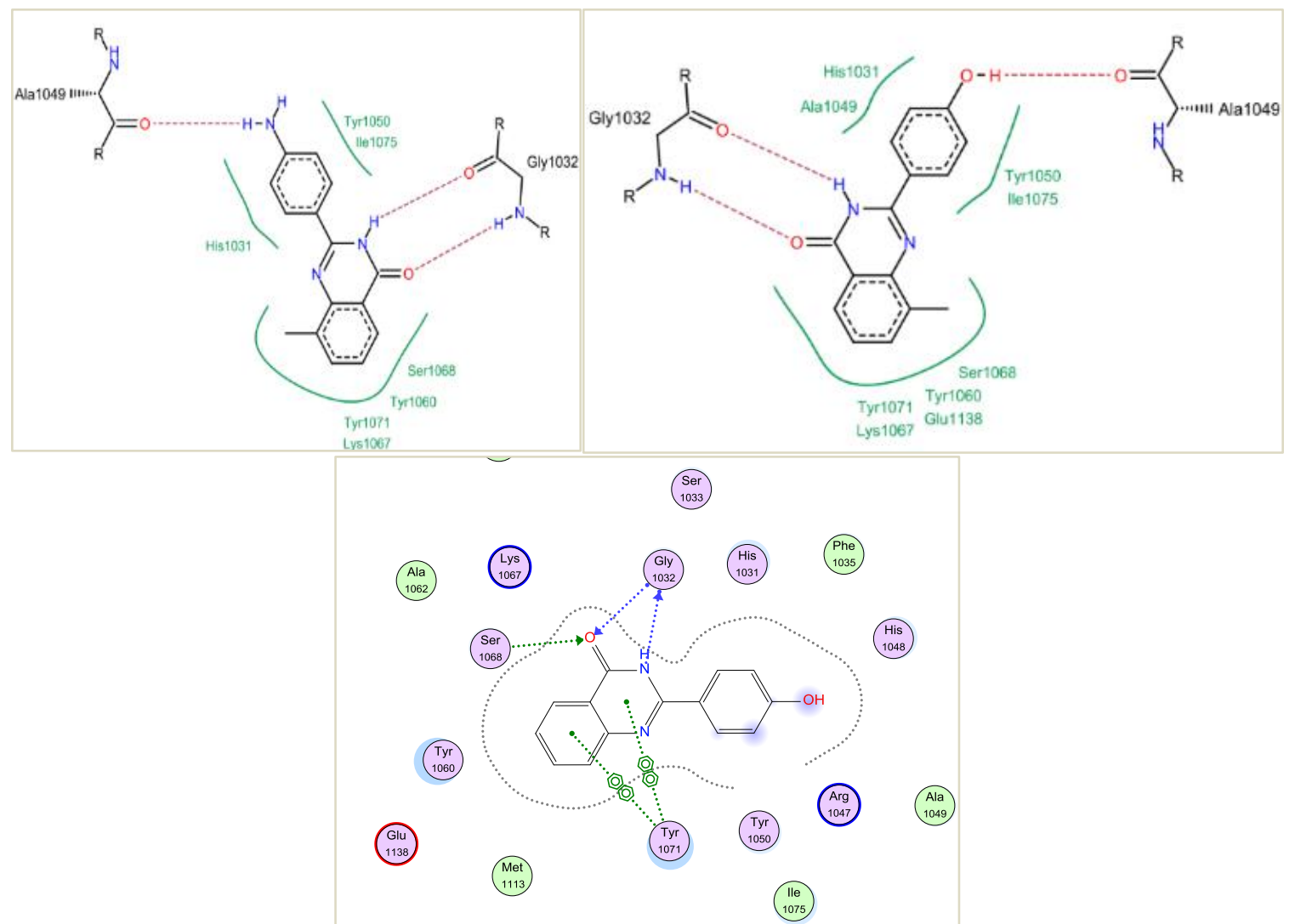

Fig. 11: 2D-pose views (right, by MOE) for compound 27 and 2D-pose (middle and left, by leadIt) for compounds 45 and 47. 4H-bonds indicated as dotted arrows with Gly1032, Ser1068, Ala1049, hydrophobic attraction force indicated as light-blue halos around the amino acid residue, with His1031, Tyr1060, Tyr1071, Ile1075, $\pi$ - $\pi$ stacking, as indicated by green dotted line, with Tyr1071, OH group with high solvent accessible surface area (blue smudge) is in the interior region of the binding pocket filled with water.

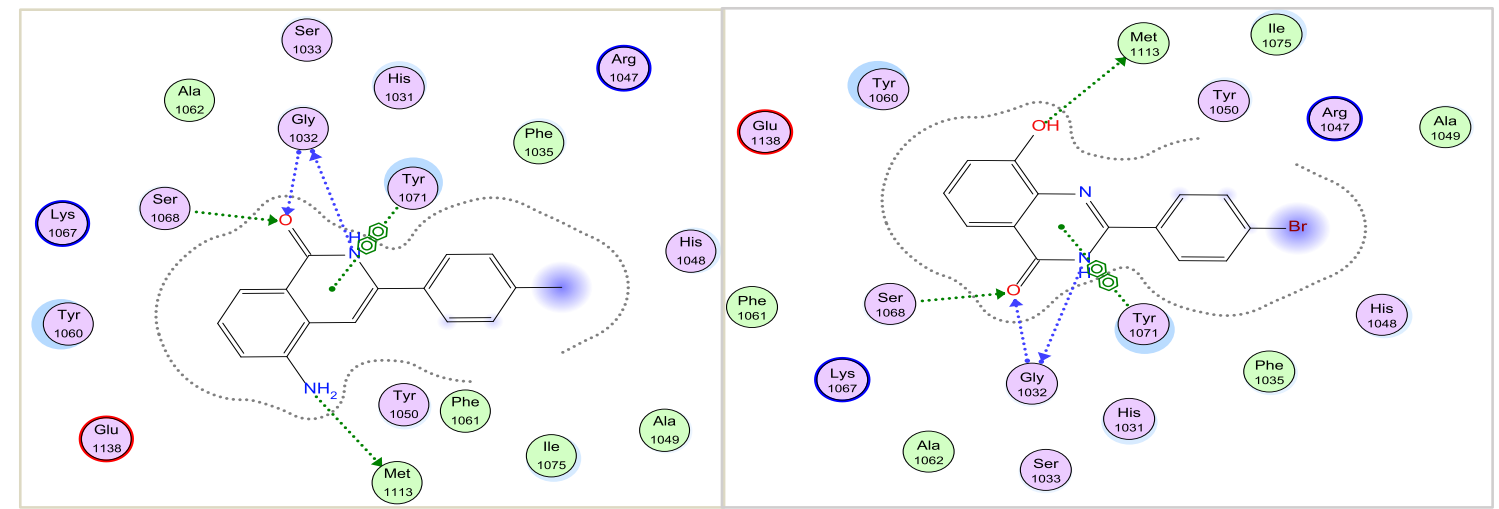

Fig. 12: Docking interaction of compound 33 (right) and compound 50 (left) on $3 \mathrm{U} 9 \mathrm{H}$.

4H-bonds formation with Gly1032, Ser1068, and Met1113, $\pi-\pi$ stacking with Tyr1071, hydrophobic attraction force with His1031, His 1048, Tyr1060, Tyr1071, Ile1075, high solvent accessible surface area of the ligands plotted directly onto the $\mathrm{Br}$ and $\mathrm{CH}_{3}$ in the form of a blue smudge.

The presence of halogens at the paraposition, especially as in the case of compound 33, demonstrated a unique feature because they increase the lipophilicity, such as $\mathrm{Br}$, and are $\mathrm{H}$-bond acceptor. As shown in Figure 12, bromide atom is located in a lipophilic pocket and formed a hydrophobic attraction force with His1048 and Ile1075. This pocket is filled with water, which could form $\mathrm{H}$-bond with $\mathrm{Br}$ as observed in the high solvent accessible surface area of the ligands plotted directly onto the $\mathrm{Br}$ in the form of a blue smudge (right). In case of compound 50,with a methyl group at the para position, ishydrophobic with high solvent accessible surface area (blue smudge) and are likely to be energetically disfavored. The high potency of compounds 28 and 48 was observed as a result of binding to the adenoside subsite because the long Cbzside-chain was extended to interact with the adenoside subsite amino acids by forming strong hydrophobic and $\pi-\pi$ stacking with Ile1075in addition to hydrophobic attraction force Phe1035 (Haikarainen1 et al., 2014). The formation of $\mathrm{H}$ bond between amino group and Ala1049 play an important role in 
increasing their activity as shown in Figures 13 and 14.Although it had the required nicotinamide pharmacophore, low potency of inhibitor 55 with 2,6-dichloro substituents is explained byits sterically disfavored orientation in active site which resulted in the absence of H-bond interaction with Ser1068 as shown in Figure 15. The presence of two chlorosubstituents at the ortho positions may make strong electrostatic repulsion with an important amino acid residue Glu1138, which decreased the complex stability. Docking calculations showed that compound 55 has the worst docking score and protein-ligand clash of 10.08as shown in Tables (1a, b \& c).

This could be the reason for lowering the potency of compound 55 compared to XAV939 which is in a good agreement with the experimental value. In case of inhibitor 58 with thiophenyl ring, its high potency may be explained by the observed H-bond with Ser1033 as shown in Figure 16. In conclusion, the results obtained from the established models, 2D, 3D-QSAR, and docking analysis, we can assess the structural requirements for selective, potent TNKS-2 inhibitor as follows: (1) nicotinamide pharmacophore is essential for activity and form important 3H-bonds with Ala1032 and Ser1068. (2) H-bond donor group like $\mathrm{OH}, \mathrm{NH}_{2}$ in $\mathrm{R} 1$ position improves the biological activity by interacting with Ala1049 as well as in R2 position by forming H-bond with Met1113 in the active site. (3) Both electron donors like $\mathrm{OCH}_{3}$ and bulky electron acceptors such as $\mathrm{Br}$ in $\mathrm{R} 1$ position increase the inhibitory activity as explained by the electrostatic and steric fields of the developed CoMFA and docking results. (4) Long chain, like $\mathrm{Cbz}$, in $\mathrm{R} 1$ position increase activity by extending outside the nicotinamide subside and binding to the adenoside subsite. (5) Thiophen ring at 3 position with sulfur as heteroatom increase activity by forming H-bond with Ser1033. (6) The molecular docking highlights the hydrophobic interactions between aromatic structure and amino acids, Tyr1060, Tyr1071, Ile1075. Substitution at the 2 ' and 6' position with chlorides at 3phenyl ring is not tolerated as explained with the CoMFA and docking analysis. Depending on the results of this study, new TNKS-2 inhibitors were designed to be synthesized and are expected to be potent inhibitors. PIC50 of proposed compounds were calculated by our developed QSAR models as shown in Table 3 .

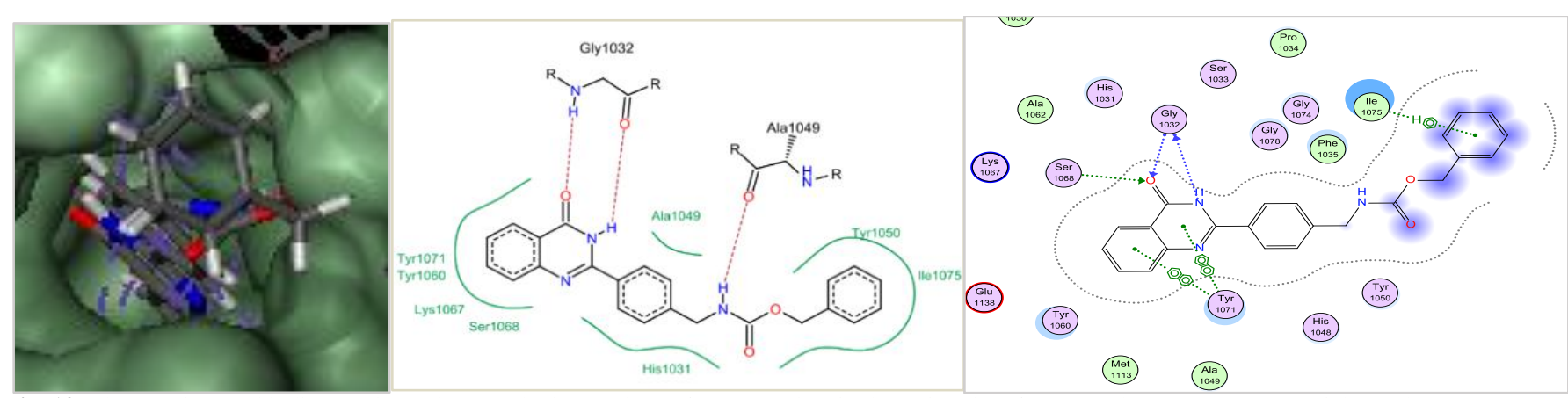

Fig. 13: The putative 2D-binding modes and molecular interactions of compound 28 in the active site of TNKS-2 by MOE on 3U9H (right) and LeadIt on $4 \mathrm{UX} 4$ (middle). 3D mode of interaction by LeadIt (left) showed the protein by molecular surface and 28 was depicted by sticks. MOE captured 3H-bonds with Gly1032 and Ser1068, $\pi-\pi$ stacking with Tyr1071 and Ile1075, strong hydrophobic attraction forces with Phe1035, Tyr1060, Tyr1071 and Ile1075, weaker hydrophobic attraction force with His1031, Tyr1050, Gly1074, and Gly1078, a hydrophobic benzyl group with high solvent accessible surface area (blue smudge) are extended outside the nicotinamide binding pocket and bind to the adenoside subside (right and left). LeadIt captured 3H-bonds with Gly1032 and Ala1049 (middle).

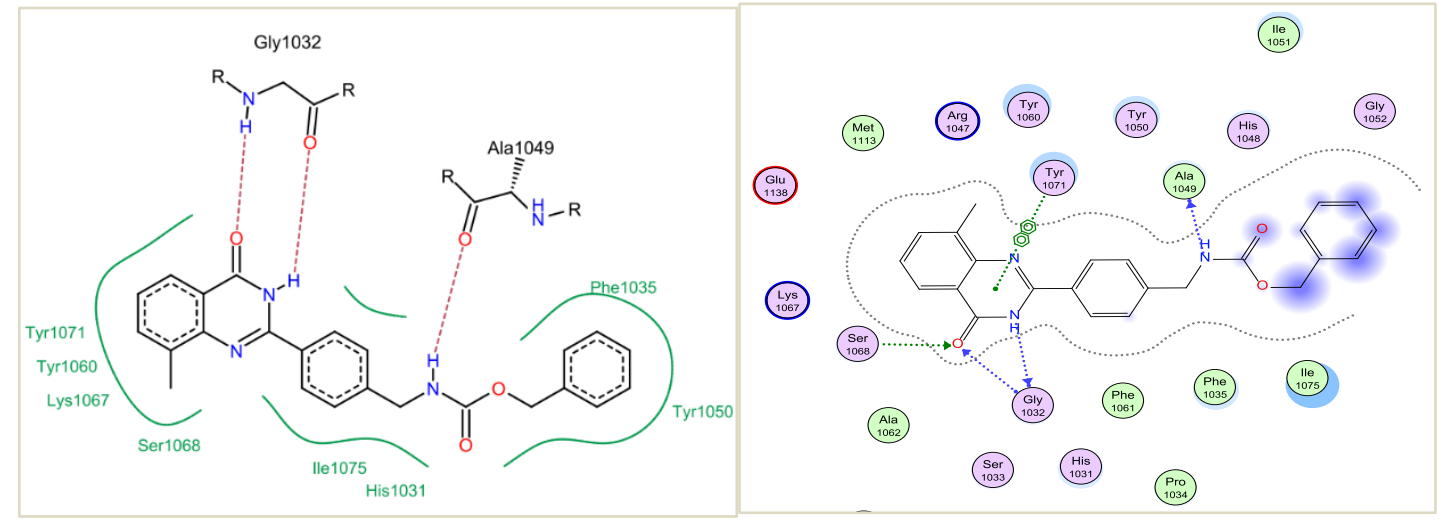

Fig. 14: 2D-binding interactions of compound 48 in the active site of TNKS-2 by MOE on 3U9H (right) and LeadIt on $3 \mathrm{KR} 8$ (left).

4H-bonds with Gly1032, Ser1068 and Ala11049, $\pi$ - $\pi$ stacking with Tyr1071, strong hydrophobic attraction forces with Tyr1050, Tyr1060, Tyr1071 and Ile1075, weaker hydrophobic attraction force with His1031, Phe1035, and His1045, a hydrophobic benzyl group with high solvent accessible surface area (blue smudge) are extended outside the nicotinamide binding pocket and bind to the adenoside subside (right). 


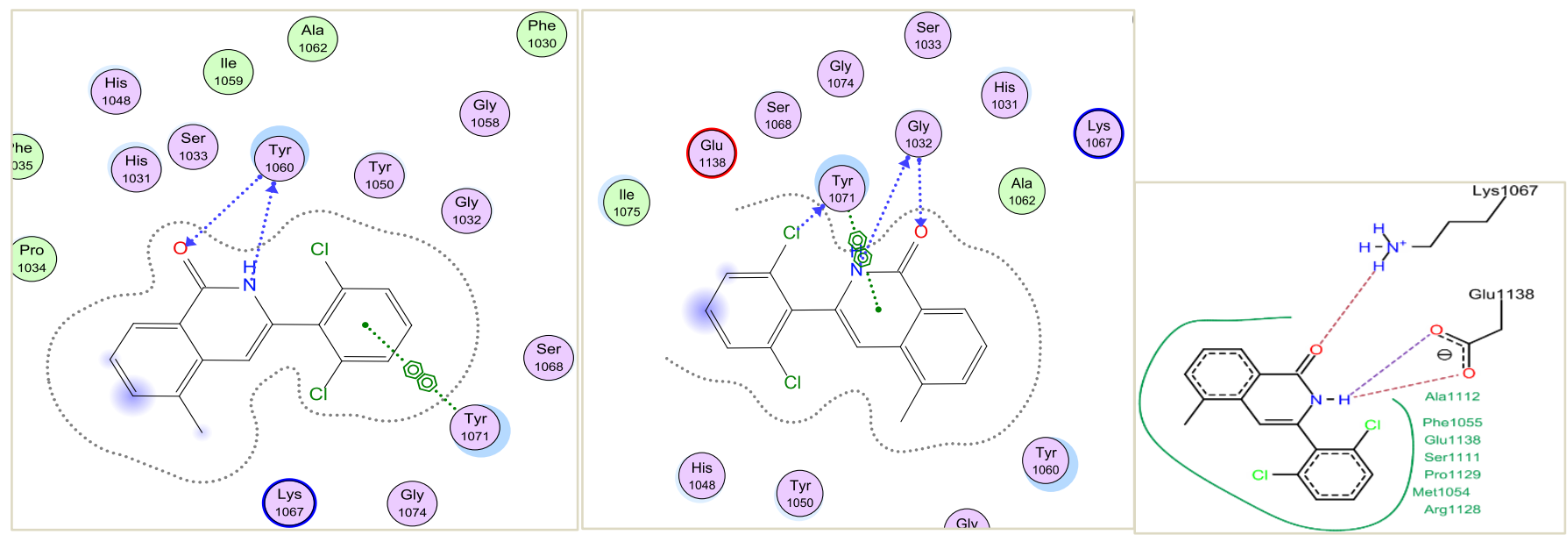

Fig. 15: 2D interaction of compound 55 in the active site of 4UX4 using LeadIT(right) and MOE (middle and left).

Improper orientation of the ligand in the active site with the absence of interaction with Ser1068 and/or Gly1032, probable repulsion with Glu1138 (left).

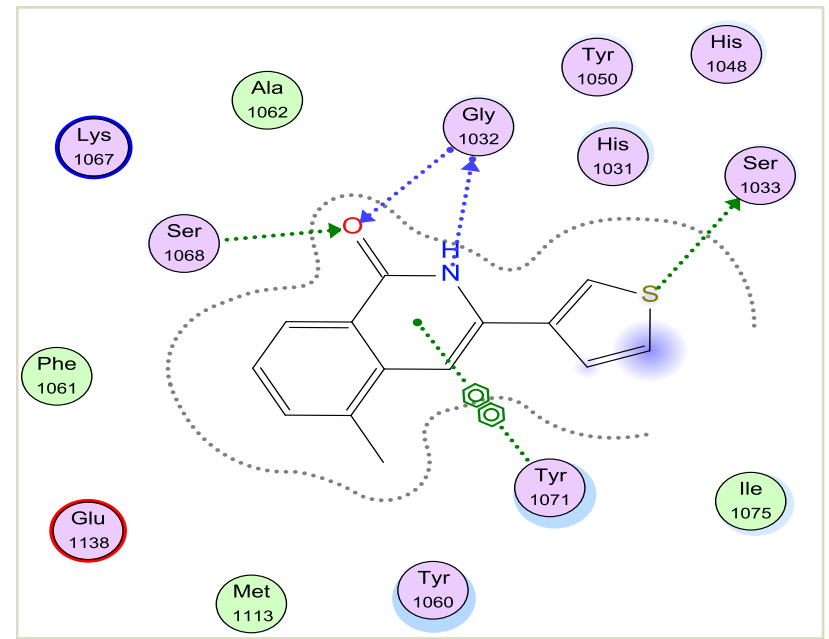

Fig. 16: $2 \mathrm{D}$ pose view of compound 58 in the active site of TNKS-2, 3U9H using MOE.

4H-bonds with Gly1032, Ser1068 and Ser1033, $\pi-\pi$ stacking with Tyr1071, hydrophobic attraction force with His1031, His1048, Tyr1060, Tyr1071 and Ile1075.

Table 3: New designed potent TNKS-2 inhibitors and their predict biological activity using our developed CoMFA and QuaSAR models.

\begin{tabular}{|c|c|c|c|c|c|}
\hline Chemical structure & Compound & $\mathbf{X}$ & R1 & $\begin{array}{c}\text { Pred PIC }_{50} \\
\text { CoMFA }\end{array}$ & $\begin{array}{c}\text { Pred PIC }_{50} \\
\text { QuaSAR }\end{array}$ \\
\hline O & 63 & $\mathrm{CH}_{2}$ & $\mathrm{CH}_{3}$ & 8.20 & 8.02 \\
\hline & 64 & $\mathrm{O}$ & $\mathrm{CH}_{3}$ & 7.74 & 6.82 \\
\hline & 65 & ${ }^{+} \mathrm{NH}_{2}$ & $\mathrm{CH}_{3}$ & 8.07 & 7.77 \\
\hline & 66 & $S$ & $\mathrm{CH}_{3}$ & 7.53 & 7.75 \\
\hline
\end{tabular}

\section{CONCLUSIONS}

A modeling study of a series of TNKS-2 inhibitors was carried out using CoMFA, 2D-QSAR, methods and docking analysis. CoMFA model included steric, electrostatic fields, MOLPROP-AREA descriptors \& showed a satisfactory statistical quality and predictive abilities as show the $\mathrm{R}^{2}$ and $\mathrm{Q}^{2}$ values. Meanwhile, the 2D-QuaSAR model generated indicating that both 2 D-descriptors (VAdjEq, BCUT_PEOE_2, BCUT_SMR_1) and 3D-descriptors (AM1_IP, PM3_HOMO, vsurf_CW*, FASA+,
FCASA+) have important influences on the ligand-receptor interaction. The predictive ability of the QuaSAR model $\left(\mathrm{R}^{2}=\right.$ $0.795, \mathrm{R}^{2}(\mathrm{cv})=0.607, \mathrm{RMSE}=0.336$, and $\left.\mathrm{RMSE}(\mathrm{cv})=0.483\right)$ was also as good as the CoMFA model. The molecular docking study discussed the appropriate binding differences between these series of compounds when interacting with TNKS-2 active side.

We discussed the structural requirements for selective, potent TNKS-2 inhibitor and designed four potent inhibitors to be synthesized in the future. 
Financial support and sponsorship: Nil.

Conflict of Interests: There are no conflicts of interest.

\section{REFERENCES}

Barkauskaite E, Jankevicius G, Ahel1 I. Structures and mechanisms of enzymes employed in the synthesis and degradation of PARP-dependent protein ADP-ribosylation. Mol Cell, 2015; 58:935-946.
BioSolvelT
$\mathrm{Gmb}$
"LeadIT."
Available

https://www.biosolveit.de/LeadIT/ [Accessed 7 February 2017].

Bregman H, Chakka N, Guzman-Perez A, Gunaydin H, Gu Y, Huang X, Berry V, Liu J, Teffera Y, Huang L, Egge B, Mullady EL, Schneider S, Andrews PS, Mishra A, Newcomb J, Serafino R, Strathdee CA, Turci SM, Wilson C, Dimauro EF. Discovery of novel, inducedpocket binding oxazolidinones as potent, selective, and orally bioavailable tankyrase inhibitors. J Med Chem, 2013; 56:4320-4342.

ChemAxon®. "MarvinSketch.": Available at: http://www.chemaxon.com/products/marvin/. [Accessed 10 January 2017]. Chi N-W, Lodish HF. Tankyrase is a Golgi-associated mitogenactivated protein kinase substrate that interacts with IRAP in GLUT4 vesicles. J Biol Chem, 2000; 275:38437-38444.

Clark MC, Cramer RD, Opdenbosch NV. Validation of the general purpose Tripos 5.2 force field. J Comp Chem, 1989; 10:982-1012.

Clark RD. OptiSim: An extended dissimilarity selection method for finding diverse representative subsets. J Chem Inform Comp Sci, 1997; 37:1181-1188

Cruciani G, Crivori P, Carrupt P-A, Testa B. Molecular fields in quantitative structure-permeation relationships: The VolSurf approach. J MolStruct (Theochem), 2000; 503:17-30.

De Rycker M, Price CM. Tankyrase polymerization is controlled by its sterile alpha motif and poly(ADP-ribose) polymerase domains. Mol Cell Biol, 2004; 24:9802-9812.

Gao J, Zhang J, Long Y, Tian Y, Lu X. Expression of tankyrase 1 in gastric cancer and its correlation with telomerase activity. PatholOncol Res, 2011; 17:685 - 690.

Gasteiger J, Marsili M. Iterative partial equalization of orbital electronegativity - a rapid access to atomic charges. Tetrahedron, 1980; 36:3219-3228

GelminiS, PoggesiM, DistanteV, BianchiS, SimiL, LuconiM, RaggiCC, CataliottiL, PazzagliM, OrlandoC. Tankyrase, a positive regulator of telomere elongation, is over expressed in human breast cancer. Cancer let, 2004; 216:81-87.

Gelmini S, Quattrone S, Malentacchi F, Villari D, Travaglini F, Giannarini G, Melina AD, Pazzagli M, Nicita G, Selli C, Orlando C. Tankyrase-1 mRNA expression in bladder cancer and paired urine sediment: preliminary experience. ClinChem Lab Med, 2007; 45: 862-866.

Gramatica P. Principles of QSAR model validation: Internal and external. QSAR Comb Sci, 2007; 26:694-701.

Gunaydin $\mathrm{H}, \mathrm{Gu}$ Y, Huang X. Novel binding mode of a potent and selective tankyrase inhibitor. PLoS One, 2012; 7: e33740.

Haikarainen1 T, Krauss S, Lehtiö L. Tankyrases: structure, function and therapeutic implications in cancer. Curr Pharm Des, 2014; 20:6472-6488

Hua Z, Bregman H, Buchanan JL, Chakka N, Guzman-Perez A, Gunaydin H, Huang X, Gu Y, Berry V, Liu J, Teffera Y, Huang L, Egge B, Emkey R, Mullady EL, Schneider S, Andrews PS, Acquaviva L, Dovey J, Mishra A, Newcomb J, Saffran D, Serafino R, Strathdee CA, Turci SM, Stanton M, Wilson C, Dimauro EF. Development of novel dual binders as potent, selective, and orally bioavailable tankyrase inhibitors. J Med Chem, 2013; 56:10003-10015.

Huang SM, Mishina YM, Liu S, Cheung A, Stegmeier F, Michaud GA, Charlat O, Wiellette E, Zhang Y, Wiessner S, Hild M, Shi X, Wilson CJ, Mickanin C, Myer V, Fazal A, Tomlinson R, Serluca F, Shao W, Cheng H, Shultz M, Rau C, Schirle M, Schlegl J, Ghidelli S, Fawell S, Lu C, Curtis D, Kirschner MW, Lengauer C, Finan PM,
Tallarico JA, Bouwmeester T, Porter JA, Bauer A, Cong F. Tankyrase inhibition stabilizes axin and antagonizes Wntsignalling. Nature, 2009; 461:614-620.

Huang S-MA, Mishina YM, Liu S, Cheung A, Stegmeier F, Michaud GA, Charlat O, Wiellette E, Zhang E, Wiessner S, Hild M, Shi X, Wilson CJ, Mickanin C, Myer V, Fazal A, Tomlinson R, Serluca F, Shao W, Cheng H, Shultz M, Rau C, Schirle M, Schlegl J, Ghidelli S, Fawell S, Lu C, Curtis D, Kirschner MW, Lengauer C, Finan PM, Tallarico JA, Bouwmeester T, Porter JA, Bauer A, Cong F. Tankyrase inhibition stabilizes axin and antagonizes Wnt signaling. Nature, 2009; 461:614-620.

Jain S, Ghate M, Bhadoriya K, Bari S, Chaudhari A, Borse J. 2D, 3D-QSAR and docking studies of 1,2,3-thiadiazole thioacetanilides analogues as potent HIV-1 non-nucleoside reverse transcriptase inhibitors. Org Med Chem Lett, 2012; 2:1-13.

Karlberg L, Markova N, Johansson I, Hammarstrom M, Schutz P, Weigelt J, Schulert H. Structural Basis for the Interaction between Tankyrase-2 and a potent Wnt-signaling inhibitor. J Med Chem, 2010; 53:5352-5255.

Kumpan K, Nathubhai A, Zhang C, Wood PJ, Lloyd MD, Thompson AS, Haikarainen T, Lehtiö L, Threadgill MD. Structure-based design, synthesis and evaluation in vitro of arylnaphthyridinones, arylpyridopyrimidinones and their tetrahydro derivatives as inhibitors of the tankyrases. Bioorg Med Chem, 2015; 23:3013-3032.

La Torre D, Conti A, Aguennouz M, De Pasquale MG, Romeo S, Angileri FF, Cardali S, Tomasello C, Alafaci C, Germanò A. Telomere length modulation in human astroglial brain tumors. PLOS ONE, 2013; 8 (5): e64296.

Lakhlili W, Yasri A, Ibrahimi Z. Structure-activity relationships study of mTOR kinase inhibition using QSAR and structure-based drug design approaches. Onco Targets Ther, 2016; 9:7345-7353.

Lehtiö L, Chi N-W, Krauss S. Tankyrases as drug targets. FEBS Journal, 2013; 280:3576-3593.

Lehtiö L, Collins R, van den Berg S, Johansson A, Dahlgren LG, Hammarström M, Helleday T, Holmberg-Schiavone L, Karlberg T, Weigelt J. Zinc binding catalytic domain of human tankyrase. J MolBiol, 2008; 379:136-145.

Li Y-P, Weng X, Ning F-X, Ou J-B, Hou J-Q, Luo H-B, Li D, Huang Z-S, Huang S-L, Gu L-Q. 3D-QSAR studies of azaoxoisoaporphine, oxoaporphine, and oxoisoaporphine derivatives as anti-AChE and anti-AD agents by the CoMFA method. J Mol Graph Model, 2013; 41:61-67.

Liscio P, Carotti A, Asciutti S, Ferri M, Pires MM, Valloscuro S, Ziff J, Clark NR, Macchiarulo A, Aaronson SA, Pellicciari R, Camaioni E. Scaffold hopping approach on the route to selective tankyrase inhibitors. Eur J Med Chem, 2014; 87:611-623.

Martino-Echarri E, Brocardo MG, Mills KM, Henderson BR Tankyrase inhibitors stimulate the ability of tankyrases to bind axin and drive assembly of $\beta$-catenin degradation-competent axin puncta. PLOS ONE, 2016; 11(3):e0150484

MOE: Molecular Operating Environment. 2014. Available at http://www.chemcomp.com/MOE-

Molecular_Operating_Environment.htm. [Accessed 17 February 2017].

Nathubhai A, Haikarainen T, Hayward PC, Munoz-Descalzo S, Thompson AS, Lloyd MD, Lehtiö L, Threadgill MD. Structure-activity relationships of 2-arylquinazolin-4-ones as highly selective and potent inhibitors of the tankyrases. Eur J Med Chem, 2016; 118:316-327.

Paine HA, Nathubhai A, Woon ECY, Sunderland PT, Wood PJ, Mahon MF, Lloyd MD, Thompson AS, Haikarainen T, Narwal M, Lehtiö L, Threadgill MD. Exploration of the nicotinamide-binding site of the tankyrases, identifying 3-arylisoquinolin-1-ones as potent and selective inhibitors in vitro. Bioorg Med Chem, 2015; 23:5891-5908.

Protein data bank "PDB Id 3KR8." Available at http://www.rcsb.org/pdb/explore/explore.do?structureId=3KR8 [Accessed 11 February 2017].

Protein data bank "PDB Id 3U9H" Available at http://www.rcsb.org/pdb/explore/explore.do?structureId=3U9H. [Accessed 7 February 2017]. 
Protein data bank "PDB Id 4UX4." Available at http://www.rcsb.org/pdb/explore/explore.do?structureId=4UX4 [Accessed 9 February 2017].

Riccio AA, McCauley M, Langelier MF, Pascal JM. Tankyrase sterile $\alpha$ motif domain polymerization is required for its role in Wnt signaling, Structure. 2016; 24:1573-1581.

Roy K. On some aspects of validation of predictive quantitative structure-activity relationship models. Expert Opin Drug Discov, 2007; 2:1567-1577.

Shultz MD, Majumdar D, Chin D, Fortin PD, Feng Y, Gould T, Kirby CA, Stams T, Waters NJ, Shao W. Structure efficiency relationship of $[1,2,4]$ triazol-3-ylamines as novel nicotinamide isosteres that inhibit tankyrases. J Med Chem, 2013; 56:7049-7059.

Stanton D, Jurs P. Development and use of charged partial surface-area structural descriptors in computer-assisted quantitative structure-property relationship studies. Anal Chem, 1990; 62:2323-2329.

SYBYL-X2.1.1, 2012, Tripos International, 1699 South Hanley Rd., St. Louis, Missouri, 63144, USA. .http://downloads.informer.com/sybyl-x/2.1/ [Accessed 10 January 2017].

Todeschini R, Consonni V, Gramatica P. Chemometrics in QSAR. Comprehensive chemometrics. ChemBiochem Data Anal, 2009; 4:129-172.

Tropsha A. Best practices for QSAR model development, validation, and exploitation, MolInf, 2010; 29:476-488.

Veerasamy R, Rajak H, Jain A, Sivadasan S, Varghese CP, Agrawal RK. Validation of QSAR models-strategies and importance. Int J Drug Des Disc, 2011; 3:511-519.

Villalobos TPJ, Ibarra1 RG, Acosta JJM. 2D, 3D-QSAR and molecular docking of $4(1 \mathrm{H})$-quinolones analogues with antimalarial activities. J Mol Graph Model, 2013; 46:105-124.

Waaler J, Machon O, Tumova L, Dinh H, Korinek V, Wilson SR, Paulsen JE, Pedersen NM, Eide TJ, Machonova O, Gradl D, Voronkov A, von Kries JP, Krauss S. A novel tankyrase inhibitor decreases canonical Wnt signaling in colon carcinoma cells and reduces tumor growth in conditional APC mutant mice. Cancer Res, 2012; $72: 2822-2832$.
Wahlberg E, Karlberg T, Kouznetsova E, Markova N, Macchiarulo A, Thorsell AG, Pol E, Frostell A, Ekblad T, Oncü D, Kull B, Robertson GM, Pellicciari R, Schüler H, Weigelt J. Family-wide chemical profiling and structural analysis of PARP and tankyrase inhibitors. Nat Biotechnol, 2012; 30:283-288

Wang H, Lu B, Castillo1 J, Zhang Y, Yang Z, McAllister G, Lindeman A, Reece-Hoyes J, Tallarico J, Russ C, Hoffman G, Xu W, Schirle M, Cong F. Tankyrase inhibitor sensitizes lung cancer cells to EGFR inhibition via stabilizing angiomotins and inhibiting YAP signaling. J BiolChem, 2016; 291:15256-15266.

Zhao X, Chen M, Huang B, Ji H, Yua M. Comparative Molecular Field Analysis (CoMFA) and Comparative Molecular Similarity Indices Analysis (CoMSIA) Studies on $\alpha_{1 \mathrm{~A}}$-adrenergic receptor antagonists based on pharmacophore molecular alignment. Int J MolSci, $2011 ; 12: 7022-7037$.

\section{How to cite this article:}

El-Hamamsy MH. Accessing the Anti-Proliferating Activity of Tankyrase-2 Inhibitors Via 2d, 3d-Qsar and Molecular Docking: Assessment of Structure Activity Relationships. J App Pharm Sci, 2017; 7 (12): 014-027. 